\title{
An Ecological Macroeconomics model: the energy transition in the EU.
}

\author{
Jaime Nieto $^{\text {ab* }}$, Óscar Carpintero $^{\text {ab }}$, Luis Fernando Lobejón ${ }^{\text {ab }}$, Luis Javier Miguel ${ }^{\mathrm{b}}$. \\ a Department of Applied Economics, Av. Valle Esgueva 6, University of Valladolid, Spain. \\ ${ }^{\mathrm{b}}$ Research Group on Energy, Economy and System Dynamics, Paseo del Cauce, s/n, University \\ of Valladolid.
}

\begin{abstract}
$\underline{\text { Abstract }}$
The European Union is going to implement the Energy Roadmap 2050 (ER2050) during the next decades pursuing its climate goals while by reducing energy use and a transition to renewables. The macroeconomic impacts of different scenarios (Ref16 and 'EUCO' scenarios) of this strategy has been reported to entail an absolute decoupling between GDP growth (and employment) and energy use. The aim of this paper is assessing the ER2050 targets with a novel modelling methodology based on Post-Keynesian Economics, i.e. demand-led economic growth and Ecological Economics, i.e. taking into account absolute biophysical (energy availability) constrains to economic growth. On this basis, a new Integrated Assessment Model has been built (MEDEAS) grounded on a methodology that combines System Dynamics and Input-Output analysis. This article presents the Economy module of MEDEAS-Europe and evaluates the ER2050 energy targets under different scenarios and policy assumptions regarding income distribution, foreign trade, productivity growth, industrial policies and a working time reduction policy. Our results show that GDP growth and employment creation may be halted if the ER2050 targets are met even considering great energy efficiency gains. In addition, the renewables share on the total primary energy supply would increase enough to reduce the energy imports dependency, but not sufficiently to meet the emissions targets. Only a Post-Growth scenario would be able to reconcile climate and employment goals, even though under energy restrictions certain PKE assumptions lose their effectiveness.
\end{abstract}

Keywords: Integrated Assessment Model, Ecological Macroeconomics, Climate Change, Energy transitions, Input-Output Analysis, Energy Roadmap 2050

*Corresponding author.

E-mail address: jaime.nieto@eco.uva.es (Jaime Nieto) 


\section{Introduction}

The IPCC special report on the impacts of global warming (IPCC, 2018) highlighted the importance of avoiding a $1.5^{\circ} \mathrm{C}$ increase in temperatures over the preindustrial levels. In order to overcome this challenge, the IPCC urges the international community to undertake a huge reduction in greenhouse gases (GHG) emissions as soon as possible. Historically, climate governance efforts have been aimed at a low-carbon economy via a shift from non-renewable (NRER) to renewable energy resources (RES). Moreover, despite the global nature of the objective and the growing interdependency between economies, climate governance has moved from multilateral -Kyoto Protocol being the most well-known compromise- to unilateral action after the Paris Agreement (Spash, 2016). For this reason, only developed countries are bound to an absolute reduction in GHG emissions. Accordingly, the European Union (EU) has committed to reducing GHG emissions by $80-95 \%$ by 2050 as compared to 1990 levels (European Commission, 2011). As presented in the EU's Energy Roadmap 2050 (ER2050), not only is a replacement of NRER for RER proposed, but also an overall reduction in energy consumption in their decarbonisation scenarios.

Furthermore, after a period of systematically reducing energy consumption from 2011 to 2016, the EU updated its Reference scenario (Ref2016) in a way that only different levels of energy reduction -even with current policies- are considered for the future (European Commission, 2016b). This update took place after a few years of energy use decline mostly driven by the economic crisis, but energy use growth started up again in 2016. A system of interconnected models is used by the EU to evaluate the Ref2016 scenario, whose core lies on the energy model PRIMES (E3MLab, 2014) and the general equilibrium macroeconomic model GEM-E3 model (Prospective Technological Studies, 2013). In addition to the Ref2016 scenario, different primary energy consumption (PEC) reduction scenarios have been included, such as $\mathrm{EUCO}+27, \mathrm{EUCO}+33$ and EUCO+40 with a PEC decrease of 27\%, 33\% and 40\% compared to the PRIMES baseline (E3MLab and IIASA, 2016). They also predict an enhancement of the European energy autonomy, based on a reduced rate of imports over total consumption. The macroeconomic impacts of the EU's energy scenarios are assessed in several reports based on different models. Despite that, these reports are unequivocal on anticipating positive economic growth and employment creation, and an efficiency-based negative relationship between the energy consumption and these macroeconomic impacts. This is valid for both the previous assessment (Cambridge Econometrics, 2013) and the updated one based on the Ref2016 and EUCO scenarios (European Commission, 2016a, 2016b), as well as for the GEM-E3 and E3ME model results for the impact assessment on EUCO scenarios (E3MLab and IIASA, 2016; Pollitt, 2016). 
Therefore, the results provided by the EU show that the lower the consumption of primary energy, the better the macroeconomic performance achieved in terms of GDP growth and employment will be. These outcomes embrace the idea of strong decoupling between energy consumption and GDP growth, as an absolute reduction in PEC occurs simultaneously to positive GDP growth. However, whereas some partial analyses back a positive relationship between renewables and employment creation and economic growth (Bowen and Hepburn, 2012; Lehr, Lutz and Edler, 2012; Kander and Stern, 2014), other scholars applying more systemic approaches show that weak decoupling ${ }^{1}$ is more likely (Csereklyei and Stern, 2015; Peng, Zhang and Sun, 2016; O'Neill et al., 2017; $\mathrm{Wu}$, Zhu and Zhu, 2018) and others even suggest the environmental and economic contradictions of such a green growth narrative (Steffen et al., 2015; O'Neill et al., 2018; Jackson and Victor, 2019; D'Alessandro et al., 2020). Moreover, other scholars going one step beyond, show a potential conflict on reducing energy use, meeting environmental goals and the maintenance of employment levels if a -widely defined- degrowth or post-growth agenda is not adopted (Krausmann et al., 2008; Victor, 2008; Jackson and Victor, 2011; Rodríguez-Huerta, Rosas-Casals and Sorman, 2017; Antal, 2018).

However, there is scarce modelling evidence that supports these critical views and concretely, little or none attention has been paid to energy availability. Several ecological macroeconomics literature reviews have been conducted (Pollitt et al., 2010; Scrieciu, Rezai and Mechler, 2013; Hardt and O’Neill, 2017) all of which finding a lack of integration of the economy with the environment, particularly concerning feedbacks from the energy systems to economic growth. Therefore, we argue that this conflict between the ER2050's forecasts and a significant proportion of the literature may be grounded on a modelling misrepresentation of the energy availability's role on the economic processes and unrealistic approaches like general equilibrium.

Consequently, our main objective is to analyse the macroeconomic impacts of the ER2050's targets under a novel modelling paradigm combining the Ecological Economics (EE) and Post-Keynesian Economics (PKE) theoretical frameworks, on the one hand, and the System Dynamics (SD) and Input-Output (IO) methodologies on the other hand. With this purpose, this article presents the Economy module of the Integrated Assessment Model (IAM) MEDEASEurope (see Figure 1). Whilst PKE provides the basis for a demand-led economic growth regime accounting with disequilibrium, EE sets the biophysical boundaries at which the economy must adapt to, i.e. energy availability. Conventional economics pictures environment-economy relationships as a source of positive (environmental services, contingent valuation, etc.) and

${ }^{1}$ Weak decoupling refers to a relative reduction in relative term, e.g. of energy use per capita or per unit of economic activity (energy use/GDP). 
negative (pollution, damage to health, etc.) externalities transversal to the circular flow of income. Ecological Economics, on the other hand, depicts the economic and social processes as embedded in and constrained by the natural systems of which they are subsystems. In turn, IO enables a systemic and sectorally disaggregated accountability of the direct and indirect carriers of the economic process. In addition, SD has been proven as a relevant methodology for economic analysis, both from conventional and heterodox approaches (Radzicki and Tauheed, 2009). The main advantage of this method consists of its capability to capture the complexity of systems, path-dependency across time and feedbacks (Uehara, Nagase and Wakeland, 2013; CapellánPérez, 2016), which allows the model to better capture social and biophysical constraints to the economy through non-linear, direct, indirect and multidirectional relationships.

By this means, MEDEAS-Europe offers a modelling framework that takes into account absolute energy constraints - disaggregated by primary energy resources- to economic growth. Hence, this article is able to assess the compatibility of achieving the climate goals through the EU's ambitious primary energy reduction targets, and their promising macroeconomic prospects. Provided that MEDEAS-Europe is a simulation IAM, the effects of different policy assumptions regarding several macroeconomic concerns, such as income distribution, labour productivity, working-time reduction and industrial structure shifts are analysed. The use of a flexible, broad set of scenarios and policy targets enables the exploration of transition pathways capable of reconciling environmental and socioeconomic objectives to 2050 .

The structure of this article is the following: section 2 describes the modelling approach as well as the scenarios and assumptions descriptions; section 3 shows the results of the outcomes through a sequential point of view, enabling a better understanding of the policies' effects; section 4 discusses these results and the methodology's potential with respect to the literature; finally, section 5 summarises the main concluding remarks and policy implications of the analysis.

\section{Methodology}

\subsection{General Overview}

MEDEAS is an IAM framework based on System Dynamics and Input-Output Analysis. It is a simulation model, regionally nested and built on dynamically-interrelated modules. As can be seen in Figure 1, the economic activity demands land, water, energy and materials to be transformed into goods and services. After this process, residuals are generated, both material which can be partially recycled- and gaseous, mainly greenhouse gases (GHG). Therefore, MEDEAS follows a socio-metabolic approach coherent with the Ecological Economics paradigm. 
Describing the entire functioning of the MEDEAS framework would exceed the purpose and extension of this article. Further detailed information can be found in Capellán-Pérez et al., 2020), extended for MEDEAS-World in Capellán-Pérez et al. (2017), , De Blas et al., (2018) for MEDEAS-Europe and for the global economy-module in (Nieto et al., 2019). The MEDEASWorld model sets the 'landscape' for the Europe model in terms of NRER availability, GHG concentration in the atmosphere and temperature change, as well as the overall world economic activity. These outcomes, in turn, affect the MEDEAS-EU model through NRER imports, climate change impacts and the foreign trade balance (Figure 1 and Figure 2). Both energy and labour demand are triggered by an I-O model combining monetary and biophysical (final energy requirements) units which subsequently we refer as a hybrid I-O approach. Thus, MEDEAS is demand-led and based on complementarity instead of perfect substitutability, which does not necessarily imply nor force either equilibrium or the optimization of the productive factors.

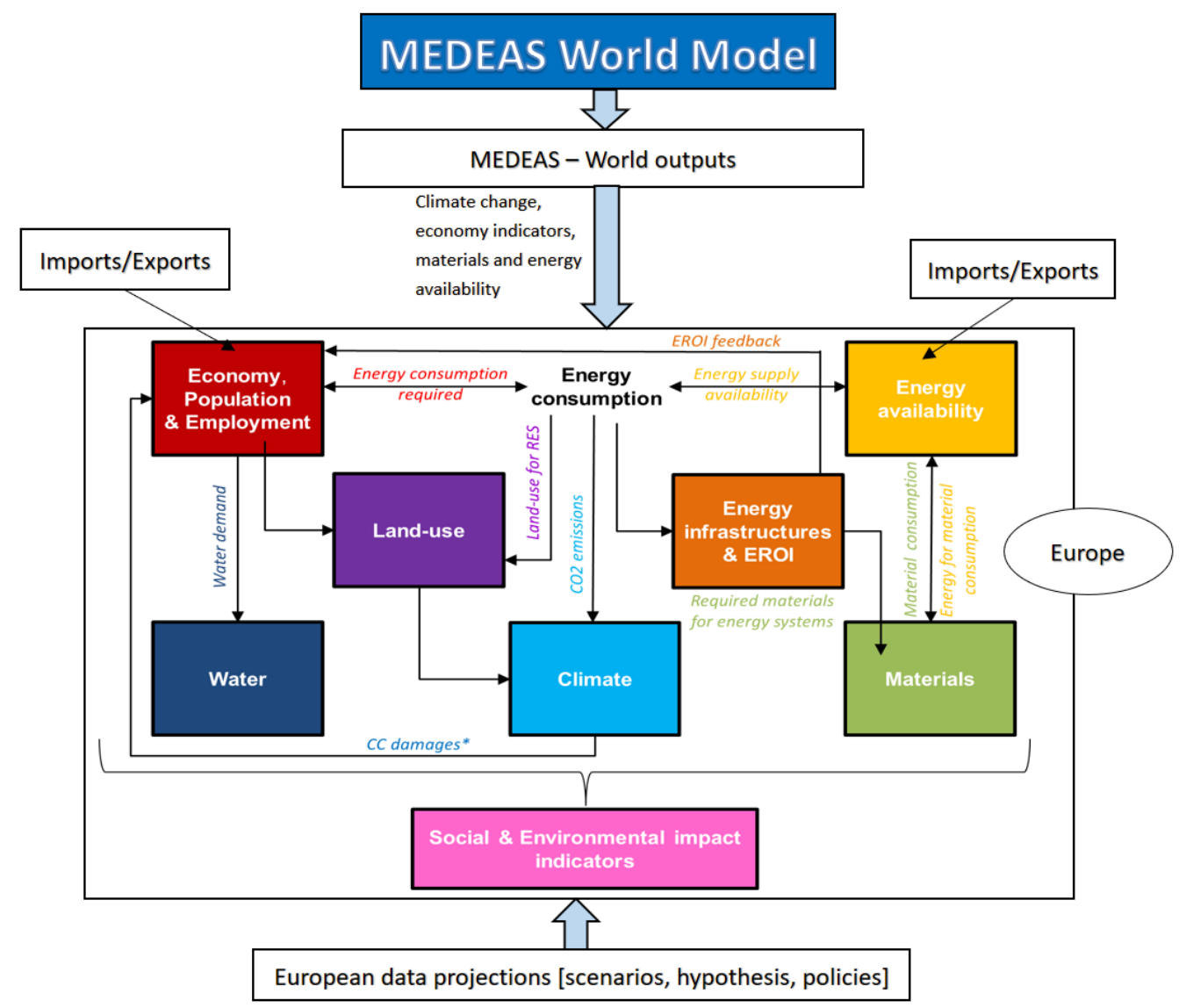

Figure 1. MEDEAS models framework. Source: Own elaboration on the basis of (De Blas et al., 2018).

* The Climate Change damage function has been disabled for this article as a conservative approach in order to shed light just on the energy use reduction effects. 
As a consequence, the employment sub-module estimates the hours of work by the skills required to produce each industry output, given the labour intensities -the inverse of labour productivity- and employment in persons, as well as the hours per worker in every industry. Both labour intensities and hours per worker are based on historic observations and then projected according to different scenarios (see section 2.3). A simplified influences diagram can be seen in Figure 2. The peculiarity of MEDEAS enabled by the SD approach is that it includes stocks whose gradual depletion feedback other variables in the model in causality loops that force the economy to adapt to resource availability. This allows the model to modulate economic growth depending on -among other key variables- energy and labour force availability, as described in section 2.2. Given the crucial role of the adaptive feedbacks in MEDEAS, it is worth clarifying the nomenclature of the variables before and after they are applied. The former variables are noted with the suffix 'Expected' as they represent the expectations of, e.g. wages paid by the employers, profits, total employment, output and GDP at the beginning of year ' $t$ '. But once the economy adapts to the boundaries of the social and biophysical systems, the model produces the 'feasible' values for these variables.

Finally, the WIOD database (Dietzenbacher et al., 2013) has been used to define the IO framework, together with its socioeconomic (Timmer et al., 2015) and environmental (Genty, 2012) satellite accounts. In addition, the EU-KLEMS database ${ }^{2}$ has been used to extend the socioeconomic variables' time series until 2015. The IO framework used comprises 35 different industries (see Appendix A) and a two-region approach with the EU28 as the main territory and the rest of the world (RoW) as the secondary one (see section 2.2.1). Appendix C shows a methodology annex on notation in order to facilitate the understanding of the equations (mostly operations between matrices, vectors and their components) in section 2.2.

${ }^{2}$ EU KLEMS is also the database which WIOD Socioeconomic Accounts relies on, so it has been chosen to maintain the consistency of the time series and industry disaggregation. See the database in: http://www.euklems.net/ 


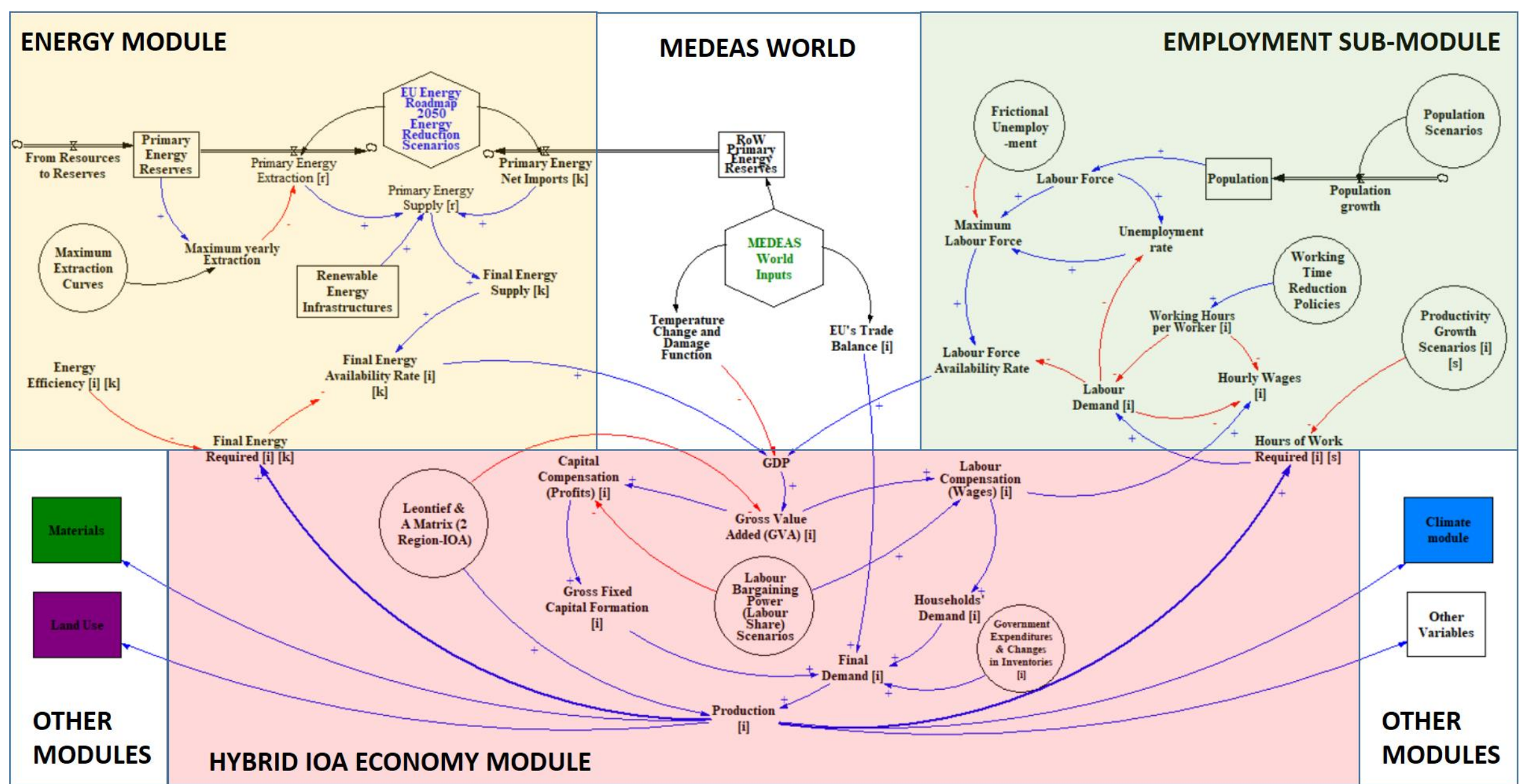

Figure 2. Simplified influences diagram of main interactions between Energy, Economy and Employment.

[i]=industries; [r]=primary energy sources; $[\mathrm{k}]=$ final energy sources; $[\mathrm{s}]=$ skills (labour]. Relationships colour code: Red arrow=negative; Blue arrow=positive; Black arrow=variable. Source: own elaboration. 


\subsection{The Economy Module}

\subsubsection{Income, Demand and Input-Output Analysis}

The Economy module (see Figure 3) is demand-led and based on IOA, as well as being reliant on expectations and income distribution. Although the module is activated with GDP growth expectations -which does not necessarily match with final demand growth because it includes all the foreign trade-, it is just considered as a means to produce the expected income that in turn determines the expected final demand before the different feedbacks adapt them to their feasible figures. Given the purpose of this article, the yearly expectations have been set to the ER2050 prospects (see sub-section 2.3). This exogenous functional distribution enables the estimation of the final demand of goods and services (see Eq.3) that eventually leads to the determination of the total amount of energy and hours of work required that are confronted with the availability of energy and labour supply, as shown in Figures 2 and 3 and described in subsections 2.2.2. and 2.2.3. Therefore, this would be the starting point of the economy module.

Thus, the module's operations start with an exogenous variation in the expected GDP growth grounded on Population and GDP per capita (GDPpc) growth scenarios. Additionally, sectoral income share scenarios enable the estimation of labour and capital compensation:

$$
\boldsymbol{\alpha}^{\mathbf{l a b}}=\left[\alpha_{j}^{\mathrm{lab}}\right]=\mathbf{w} \cdot \mathbf{g v a}^{-1}, \boldsymbol{\alpha}^{\mathbf{c a p}}=\left[\alpha_{j}^{\mathrm{cap}}\right]=\mathbf{k} \cdot \mathbf{g v a}^{-1} ; \quad \mathrm{j} \in 1 \ldots 35
$$

With ' $\mathrm{j}$ ' being the subscript for the 35 industries, $\boldsymbol{\alpha}^{\mathbf{l a b}}$ and $\boldsymbol{\alpha}^{\text {cap }}$ the vectors of sectoral labour and capital shares, $\mathbf{w}=\left[w_{j}\right]$ and $\mathbf{k}=\left[k_{j}\right]$ the vectors of sectoral labour and capital compensation - i.e., wages and gross profits- and gva $=\left[g v a_{j}\right]$ the expected sectoral gross value added vector. Therefore, income is easily obtained by solving Eq. 1 for $\mathbf{w}$ and $\mathbf{k}$. For the sake of simplicity, the expected GDP growth rate has been taken as the gva`s yearly growth. 


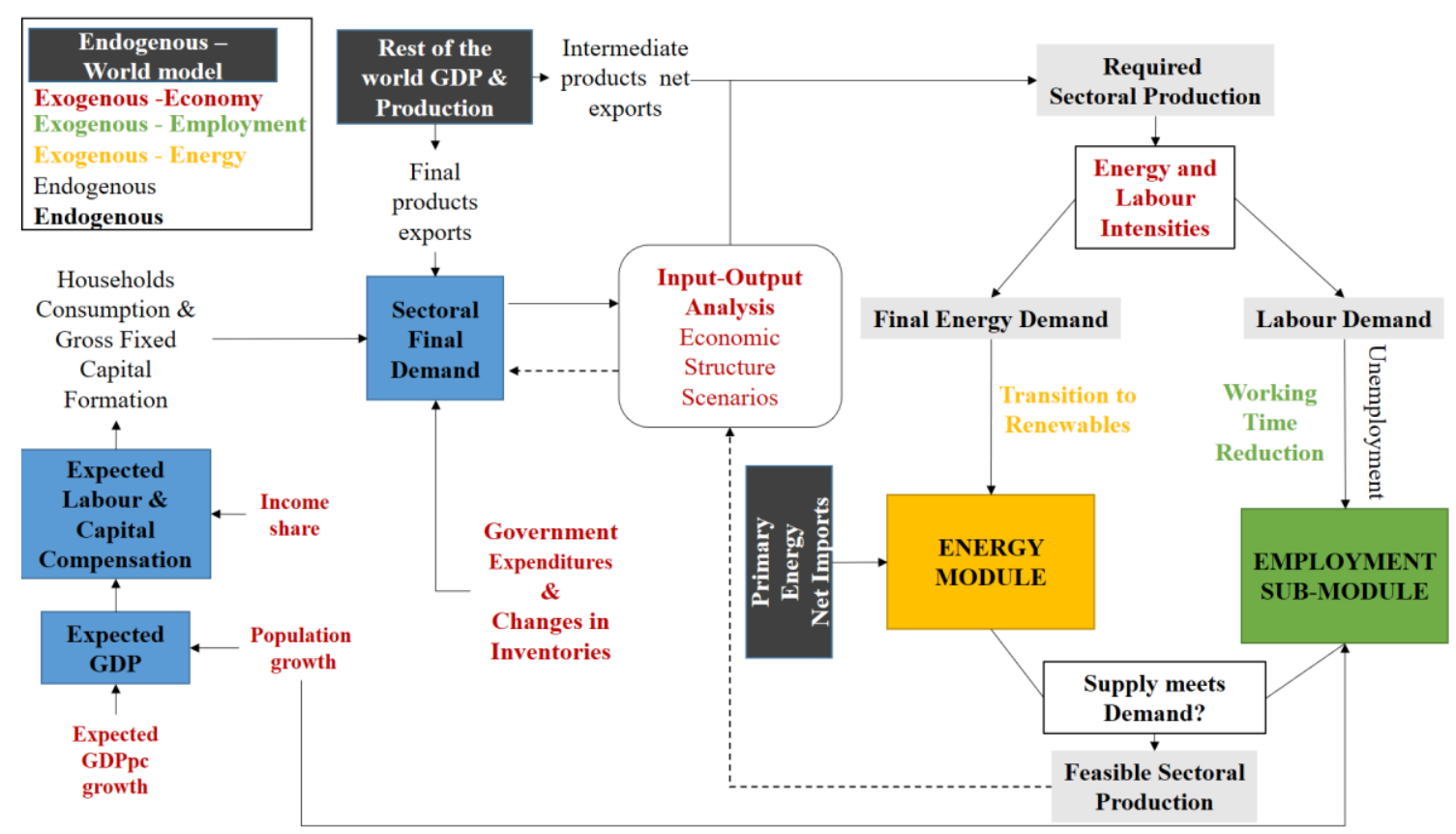

Figure 3. Schematic overview of the Economy module and main interactions. Source: own elaboration.

Hence, the module's functioning depicts a starting point where employers decide the salaries they are willing to pay in year ' $t$ ', based on the structural income distribution -that could be understood as the labour bargaining power- and the GDP growth expectations. By means of this process, the economic agents know their expected income, which is the main driver of final demand (fd) by different institutional sectors:

$$
\text { fd }=\mathbf{c}+\text { gfcf }+ \text { g }+ \text { exp }+ \text { invent }
$$

With $\mathbf{c}=\left[c_{i}\right]$ standing for sectoral households' consumption, $\mathbf{g f c} \mathbf{f}=\left[g f c f_{i}\right]$ for sectoral Gross Fixed Capital Formation (i.e., real investment), $\mathbf{e x p}=\left[g f c f_{i}\right]$ for the sectoral final products and services exports, $\mathbf{g}=\left[g_{i}\right]$ for sectoral government expenditure and invent $=\left[\right.$ invent $\left._{i}\right]$ for sectoral changes in inventories and valuables. Whereas the latter two are considered a constant proportion of sectoral final demand based on historical data, the rest are estimated with econometric panel data regressions. Although they depend on their relevant explanatory variables, they share a common structure as follows:

$$
\ln \left(\mathrm{Y}_{\mathrm{i}, \mathrm{t}}\right)=\beta_{0}+\beta_{1 i}\left(\operatorname{Sec}_{i}\right)+\beta_{2} \ln \left(\operatorname{Inc} c_{t}\right)+\beta_{3} \ln \left(\operatorname{Inc} c_{t-1}\right)
$$

$Y_{i, t}$ being the sectoral dependent variable for either $\mathbf{c}, \mathbf{g f c f}$ or $\exp$ in year $\mathrm{t}, \beta_{0}$ the constant term of the intercept, $\beta_{1 i}$ the variable term of the intercept regarding the different industries, $I n c_{t}$ 
the relevant income in year $t$-i.e., labour compensation for $\mathbf{c}$, capital compensation for $\mathbf{g f c f}^{\mathbf{3}}$ and the rest of the world's (RoW) GDP for exp. In the case of exp, it also depends on the real effective exchange rate. It is important to note that, whereas $I n c_{t}$ depends on expectations, its lagged value depends on last year's GDP, i.e., it is conditioned by all the modules' feedbacks (energy, employment) and the world economy downstream effect, implying path-dependency. These relevant feedback loops are described in the following sections. Because MEDEAS is a hierarchical, nested set of models, the world's economy performance boosts or slows down Europe's rate of growth via exp and the intermediate products trade balance calculated through the Input-Output Tables (IOTs). This will enhance or diminish the initial expected GDP growth, implicitly assuming that employers are not able to foresee the world's economic behaviour. IOA is a well-known methodology (Miller and Blair, 2009) based on the complementarity of productive factors and which is able to account for direct and indirect production requirements to satisfy variations in final demand. This framework departs from the basic accountability identity whereby sectoral production is the summation of domestic and foreign intermediate -the inputs that industries need to purchase from others to produce their output- and final demand (see Eq.5). By including invent, it assumes that mismatches between demand and supply are regular in the economy. The specific combination of inputs required from other industries to produce each industry's output is given by the technical coefficient matrix or technological matrix $\mathbf{A}=\left[a_{i j}\right]$, with:

$$
a_{i j}=\frac{z_{i j}}{x_{j}} \quad \mathrm{i}, \mathrm{j} \in 1 \ldots 70
$$

where $a_{i j}$ is the technical coefficient for the intersection between industry ' $\mathrm{i}$ ' -by rowsand ' $\mathrm{j}$ ' -by columns-, $z_{i j}$ is the monetary value of intermediate consumption of industry ' $\mathrm{j}$ ' from industry ' $\mathrm{i}$ ', and $x_{j}$ the output produced by industry ' $\mathrm{j}$ '. In a two-region matrix, as in MEDEAS$\mathrm{EU}$, intermediate products can be purchased from domestic or foreign industries and therefore, a 70x70 A matrix is used in this article. Although the current state of art in World IOT databases is strong enough to operate with a multi-regional framework, it is not the purpose of this analysis to conduct a consumption-based assessment of the biophysical carriers of domestic production. Therefore, a cleaner yet consistent two-region approach has been adopted to facilitate the

${ }^{3}$ This would be fully consistent with the Post-Keynesian approach whereby investment depends on profitability (Lavoie, 2014). Moreover, capital compensation has been used due to data availability, yet it is determined by the profit share, which is compatible with the Post-Kaleckian (Bhaduri and Marglin, 1990)investment function. 
understanding of the results. Applying the definition of the A matrix, we can develop the fundamental accountability identity of IOA:

$$
\mathbf{x}=\mathbf{A} \cdot \mathbf{x}+\mathbf{f d} \rightarrow \mathbf{x}=(\mathbf{I}-\mathbf{A})^{-1} \cdot \mathbf{f d} \rightarrow \mathbf{x}=\mathbf{L} \cdot \mathbf{f}
$$

where $\mathbf{x}=\left[x_{j}\right]$ is the sectoral production vector, $\mathbf{I}$ is the identity matrix and $\mathbf{L}=\left[l_{\mathrm{ij}}\right]=$ $(\mathbf{I}-\mathbf{A})^{-1}$ the so-called Leontief matrix measuring the production sensitivity to final demand variations. Extending this to a two-region framework, the European Union's (EU) production is:

$$
\mathbf{x}^{\mathrm{EU}}=\mathbf{L}^{\mathrm{EU}-\mathrm{EU}} \cdot \mathbf{f} \mathbf{d}^{\mathrm{EU}}+\mathbf{L}^{\mathrm{EU}-\mathrm{RoW}} \cdot \mathbf{f} \mathbf{d}^{\mathrm{RoW}}
$$

Eq. 6

The superscripts indicate the two regions according to Figure 4. For the sake of simplicity, we subsequently refer to the European production $\mathbf{x}^{\mathrm{EU}}$ as simply $\mathbf{x}$. This means that the EU's production is not only dependent on the structural composition of domestic industries, but also on the foreign ones too. Finally, from a demand-side approach, GDP equals ${ }^{4}$ :

$$
\mathrm{GDP}=\sum_{i=1}^{35} g v a_{j}=\sum_{i=1}^{35}\left(f d_{i}^{E U}+z_{i}^{E U-R O W}-z_{i}^{R o W-E U}\right)
$$

\begin{tabular}{|c|c|c|c|c|c|}
\hline$I C^{E U-E U}$ & $I C^{E U-R o W}$ & $A^{E U-E U}$ & $A^{E U-R o W}$ & $L^{E U-E U}$ & $L^{E U-R o W}$ \\
\hline$I C^{R o W-E U}$ & $I C^{\text {RoW-Row }}$ & $A^{R o W-E U}$ & $A^{\text {RoW-Row }}$ & $L^{R o W-E U}$ & $L^{\text {RoW-Row }}$ \\
\hline
\end{tabular}

Figure 4. Two-Regions Europe-Rest of the World simplified Input-Output framework.

Source: own elaboration.

${ }^{4}$ GVA and GDP are measured at basic prices, i.e., including taxes less subsidies on production but excluding taxes on products (typically, value added taxes). 


\subsubsection{Energy-Economy Feedback}

The energy-economy feedback enables a non-linear, hierarchical energy-economy nexus to be traced whereby, if energy availability is lower than demanded to reach the expected GDP growth, then the actual growth rate will suffer a slowdown. The MEDEAS Energy module receives the final energy demand from the Economy module and then takes the primary energy resources from the environment and transforms them into final energy as depicted simply in Figure 2. This configures a negative, or stabilising feedback loop whereby GDP growth increases energy demand -unless energy efficiency offsets this growth- reducing energy availability and eventually the growth capacity of the GDP. Hence, GDP growth must adapt to the energy availability, forced by the ER2050 energy targets in this article.

It goes beyond the purpose of this article to thoroughly describe the Energy Module, which is explained in depth in section 2.3 in De Blas et al., (2018) and in (Capellán-Pérez et al., 2020). However, in order to provide a context for the final energy supply to the economy, it is important to know that it is conditioned by assumptions made on RER installed capacity growth rates, depletion curves of domestic NRER, energy policy scenarios, and energy efficiency gains (see section 2.3). During the transformation process from primary to final energy, it also takes land and materials in order to deploy the energy infrastructures as new capacity is being installed. Final energy is broken down into five different types: solids, liquids, gases, electricity and heat. Each one, in turn, is disaggregated by the primary energy resources that supply them. By operating a hybrid IOA (Leontief, 1970; Miller and Blair, 2009), the final energy demand is estimated by sectors -both direct and indirect requirements- and final energy carriers. Final energy demand by $k \in 1 \ldots 5$ energy carriers, $\mathbf{f e d}=\left[f_{e} d_{k}\right]$, is the sum of the final energy demand made by ' $j$ ' $\in 1 \ldots 35$ industries fed_ind $=\left[\right.$ fed_ind $\left._{k}\right]=\sum_{j=1}^{35} f_{-} e d_{-} i n d_{k j}$ and households fed_hh $=\left[f e d_{-} h h_{k}\right]$. The energy coefficients -i.e., energy intensities- are taken from WIOD's historical data and then projected according to scenarios (see section 2.3). Both are also split into energy intensities for industries $\mathbf{E} \_\mathbf{I N D}=\left[e_{-} i n d_{k j}\right](5 \times 35$ matrix $)$ and for households, $\mathbf{e}_{-} \mathbf{h h}=\left[e_{-} h h_{k}\right](1 \times 35$ vector $)$. Eq. 8 provides the identity whereby $f e d_{-} i n d_{k j}$ is estimated, Eq.9 the estimation of $f e d_{-} i n d_{k}$ and Eq.10 the disaggregated estimation of total final energy demand $f e d_{k}$ by the energy carrier. 


$$
\begin{aligned}
& e_{-} i n d_{k j}=f e d_{-} i n d_{k j} \cdot x_{j}^{-1} \rightarrow f e d_{-} i n d_{k j}=e_{-} i n d_{k j} \cdot x_{j} \\
& \text { fed_ind }_{k}=\sum_{j=1}^{35}\left(e_{-} i n d_{k j} \cdot x_{j}\right) \\
& f e d_{k}=f e d_{-} h h_{k}+f e d_{-} i n d_{k}=e_{-} h h_{k} \cdot \mathbf{c}+\sum_{j=1}^{35}\left(e_{-} i n d_{k j} \cdot x_{j}\right)
\end{aligned}
$$

Then, the final energy use feu $=\mathbf{f e u}$ ind $+\mathbf{f e u} \_\mathbf{h h}=\left[\mathrm{feu}_{k}\right]=\sum_{j=1}^{35} f e u_{-} i n d_{k j}+$ $f e u_{-} h h_{k}$ is calculated, after checking whether the energy system was able to supply all the final energy that was demanded to satisfy the needs of a growing GDP. An assumption has been made that all the possible energy shortages' influence is production-based and, therefore, absorbed by industries. Considering this:

$$
\text { feu_ind }_{k j}=\text { fed_ind }_{k j} \cdot \varepsilon ; \quad \varepsilon=\operatorname{Min}\left(1, \frac{f e s_{k}}{\text { fed }_{k}}\right) \quad 0<\varepsilon \leq 1
$$

where $\varepsilon$ is a shortage coefficient which amounts to either 1, if all total energy carriers are sufficiently supplied including household demand, i.e., $f e d_{k}=f e s_{k}$, or the fraction representing the relative scarcity otherwise; thus making the final energy use lower than demanded $\left(f e u_{-} i n d_{k j}<f e d_{-} i n d_{k j}\right)$ for the production requirements of the economy. As there is no assumption of perfect substitutability for neither economic nor energy inputs, the scarcer final energy source (i.e., the minimum quotient for $\varepsilon$ in Eq.11) determines the reduction in the sectoral output. Subsequent periods bring about the energy substitution and energy use reduction per unit of output both in industries and households. Thus, the feasible energy use imposes a new feasible output $\mathbf{f} \_\mathbf{x}=\left[f_{-} x_{j}\right]$ by conducting the inverse process, as in Eq.8, and then substituting by Eq. 11:

$$
\mathbf{f} \_\mathbf{x}=\widehat{\mathbf{E}_{-} \mathbf{I N D}}{ }^{-1} \cdot \mathbf{f} \text { eu_ind }=\widehat{\mathbf{E}_{-} \mathbf{I N D}}{ }^{-1} \cdot \mathbf{f e d} \_ \text {ind } \cdot \operatorname{Min}\left(1, \frac{f e s_{k}}{f e d_{k}}\right)
$$

Hence, considering that fed_ind depends on the sectoral output (Eq. 8) that the economy requires to satisfy demand (Eq.5), which in turn depends on expectations and income inequality (Eqs.1-3), the economic output is a function of the final energy intensity, final energy supply, domestic economic structure ( $\mathbf{L}^{\mathrm{EU}-\mathrm{EU}}$ ) and final demand (fd), expectations, income inequality and foreign trade ( $\mathbf{L}^{\mathrm{EU}-\mathrm{RoW}}$ and $\left.\mathbf{e x p}\right)$. 


\subsubsection{Employment sub-module and Labour feedback.}

The Employment sub-module is Post-Keynesian, Kaleckian (Kalecki, 1971; Lavoie, 2015) inspired and applied to an IOA framework. According to the Post-Keynesian theory of employment, it is determined by aggregated demand instead of by the relative price of labour, i.e., wages, as Neoclassical Economics states (Hicks, 1968; Boyer and Smith, 2001). Also, unlike in Neoclassical Economics, involuntary unemployment is considered, including technological unemployment. According to this situation, a reduction in employment can be expected unless wages increase in step with or more than productivity, so the aggregate demand can offset the relative reduction in labour demand (Nell, 2005). Besides, in the short run, labour cannot be substituted by capital assuming fixed technical coefficients, which is very suitable for the InputOutput methodology used in MEDEAS. WIOD-Socioeconomic Accounts (Timmer et al., 2015) and EUKLEMS have been used, so working hours per person engaged is the basic unit of analysis. It has been broken down by industries and three labour skills: low, medium and high. Unfortunately, the skills disaggregation is lost for numbers of people employed and working time in order to avoid extremely crude assumptions. The process likewise begins the energy-economy feedback, because it also follows an IO hybrid approach. According to this, labour demand in hours of work can be expressed as:

$$
\mathbf{h}=\mathbf{Y}^{-1} \cdot \mathbf{x}
$$

with $\mathbf{h}=\left[h_{s j}\right]$ being the labour demand in hours by skills 's' $\in 1 \ldots 3$ (low, medium and high), and sector ' $\mathrm{j}$ '; $\mathbf{Y}=\left[y_{s j}\right]$ the matrix of labour productivity by sectors and skills. This means that $\mathbf{Y}^{-1}$ is the labour intensity measured as the hours of work per unit of output $\left(\frac{h_{s j}}{x_{j}}\right)$. After that, in order to obtain the number of workers required $\mathbf{l d}=\left[l d_{j}\right]$, the total hours of work by sector $h_{j}=$ $\sum_{s=1}^{3} h_{s j}$ is divided by the hours per worker by sector $\mathbf{h p w}=\left[h p w_{j}\right]$ :

$$
l d_{j}=\frac{h_{j}}{h p w_{j}}=\frac{\sum_{s=1}^{3}\left(y_{s j}^{-1} \cdot x_{j}\right)}{h p w_{j}}
$$

Therefore, the level of employment is a positive function of the aggregated demand and a negative function of productivity, as well as the hours per worker-meaning that a working time reduction (WTR) policy would increase labour demand in persons employed. Then, hourly wages $\mathbf{h} \_\mathbf{w}=\left[h_{-} w_{j}\right]$ by sector are the result of the following equation: 


$$
w_{j}=h p w_{j} \cdot h_{-} w_{j} \cdot l d_{j} \rightarrow h_{-} w_{j}=\frac{w_{j}}{h p w_{j} \cdot l d_{j}} \rightarrow h_{-} w_{j}=\frac{\alpha_{j}^{\mathrm{lab}} \cdot g v a_{j}}{h p w_{j} \cdot l d_{j}}
$$

From a static perspective, Eq.15 shows a negative relationship between labour demand and hourly wages that, as we shall see in the results and discussion sections, operates differently from a dynamic point of view. It depends on whether it was a change in aggregate demand, productivity or working hours that triggered the labour demand variation (see Figure 2). Additionally, and crucially, it also depends on the initial situation being below or on full employment. All these aspects are discussed in section 4. Finally, the main novelty introduced in this employment model is the inclusion of a feedback loop from labour supply availability to the feasible total output. So, as with the energy-economy feedback, if the labour force is not large enough to meet the labour requirements of the GDP growth, total output is cut by the same proportion as the lack in the labour force.

$$
l d^{\prime}{ }_{j}=l d_{j} \cdot \lambda ; \quad \lambda=\operatorname{Min}\left(1, \frac{L F}{L D}\right) ; 0<\lambda \leq 1
$$

where $L F$ represents the total labour force, $\lambda$ the labour availability coefficient and $L D=\sum_{j=1}^{35} l d_{j}$ the total economy-wide labour demand. $L F$ is estimated as a proportion of the population which evolves at the same rate as the 1995-2015 historical observations. Additionally, $L F$ is considered as completely inelastic, an assumption consistent with the Post-Keynesian framework, meaning that we assume that if the labour force is available, all posts demanded by firms are covered. In order to enhance the realism of the outcomes, a $2 \%$ frictional unemployment rate is assumed, so the actually available $L F$ is $2 \%$ lower than that estimated with population growth.

\subsection{Definition of scenarios.}

The main capability of the MEDEAS model is to estimate the trends that can be expected in the future under different scenarios and policy sets. Here, we distinguish between general assumptions, scenarios and policy targets. All of them are related to variables or parameters that are inputs in the model that affect the outcomes of the simulations differently. Assumptions referred to are arguable, but based on the literature or policy-targets with the explicit intention of evaluation. Scenarios describe different pathways that can be expected in the context of high uncertainty, normally as a combination of coherent assumptions. Policy targets are socioeconomic targets that depend to some extent on the actions of the policymakers in order to assess their potential effects on the system. In this article, we set two different frameworks for scenarios. 
Firstly, we define a Base scenario on which additional assumptions are added in order to evaluate their cumulative effects. Secondly, we propose three more typical scenarios based on different combinations of assumptions and policies: BAU, Green Growth and Post-Growth. The Base scenario assumes no energy constraints, a good global economic performance, a static economic structure (A Matrix) and primary income distribution, as well as productivity growth following the historical trends (see Figure 5 (a) and Appendix B). Subsequent assumptions are added on top of that Base scenario:

i/ Energy Roadmap (ER50): geological limits in domestic extraction are included following the Mohr et al., (2015) and EGW (2013) 'Best Guess' for every primary energy resource's depletion curve. The REF16, EUCO27, EUCO33 and EUCO40 scenarios are imposed as a reduction in the domestic primary energy extraction and also in net imports. This constraint has been applied to all the primary energy resources in the ER50: oil, coal, gas and uranium. Although the EUCO scenarios stop by 2030, they have been projected until 2050 (see Appendix B). Due to statistical discrepancies and a lower disaggregation detail in the PRIMES model, growth rates have been taken and applied to the MEDEAS data projections. Moreover, as a cautionary measure and to give flexibility to the system, a $+25 \%$ primary energy use (both domestic and imported) buffer is allowed for all resources. Energy efficiency follows the current trends in REF16, whereas the EUCO scenarios increase by $27 \%, 33 \%$ and $40 \%$ against the Base scenario, as stated by the EUCO storylines. The undertaking of a rapid transition towards RER will also be considered. Finally, GDP and population growth expectations are the same as those considered in the ER50 reports.

ii/ World Limits (WoLim): a MEDEAS-World scenario using worst-based simulations (Nieto et al., 2019) with energy constraints consistent with the global GDP growth moderation projections (Hawksworth, 2017; Leimbach et al., 2017) is assumed.

iii/ Lower productivity growth (LowProd): as the historical data is suggesting, especially in a context of lower access to highly profitable energy resources (Victor, 2019; Brockway et al., 2019).

iv/ Structural Change (SCh): Different policies are then developed to react to the previous outcomes: industrial policy oriented towards a modern, efficient economic structural change combined with emissions reduction capacity, represented by Germany ${ }^{5}$.

v/ Pro-labour policies (Lab): a working time reduction (WTR) together with an increase in labour bargaining power via raising the labour share e and, therefore, total wages.

${ }^{5}$ The criteria consisted of selecting a large European country with an efficient economic structure and good emissions reductions indicators (32\% lower than 1990). 
a) Sequential Scenarios

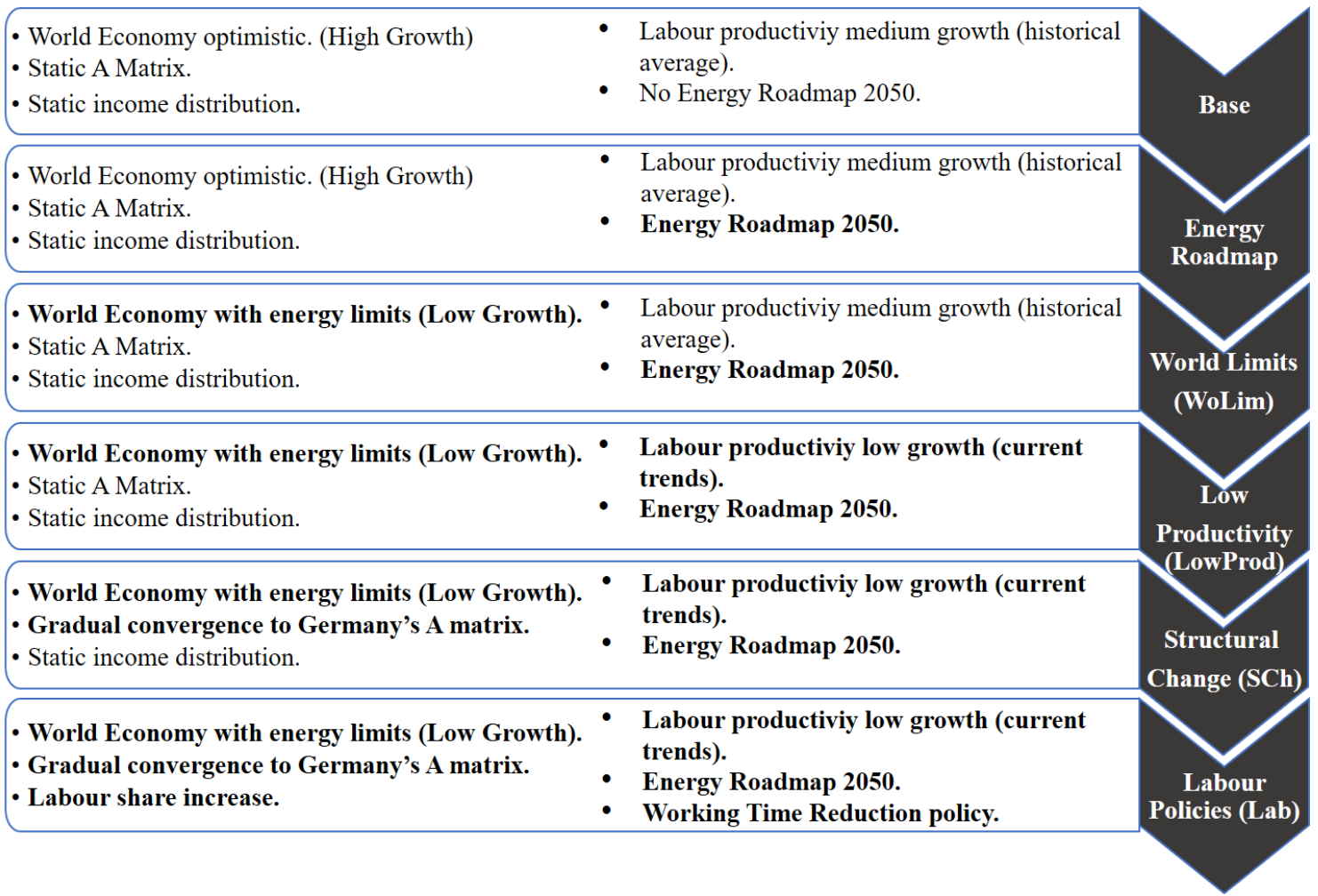

b) Storylines

\begin{tabular}{|l|l|l|l|}
\hline \multicolumn{2}{|c|}{ Variable } & \multicolumn{2}{c|}{ BAU } \\
GDP Expectations & SSP2 & SSP1 & Low \\
Population growth & SSP2 & SSP1 & Low \\
A Matrix & Static & Target: Germany & Target: Ad-hoc* \\
Income Distribution & Current trends & Pro-labour & High pro-labour \\
Productivity Growth & Current trends (Low) & Medium & Declining \\
Working Time Reduction & No & No & Yes \\
Renewables Installed Capacity Growth & Low & High & High \\
Energy Efficiency Growth & Ref 2016(Low) & EUCO33 (High) & EUCO40 (High+) \\
Energy Roadmap TPES restriction & Ref 2016 & EUCO33 & EUCO 40 \\
\hline
\end{tabular}

Figure 5. Sequential scenario (a) and storylines framework (b).

Source: Own elaboration.

* An ad-hoc A matrix favouring the less energy intensive and more labour intensive sectors to the detriment of the more energy intensive and less labour intensive sectors is applied (see Appendix B). 
The framework of the other scenarios, i.e., the comprehensive storylines, allows the combination of scenarios and policies according to recognizable, consistent future pathways of the socioeconomic landscape (see Figure 5 (b) and Appendix B). These scenarios have been depicted as follows:

1) A BAU scenario based on current trends. The SSP2, also defined as 'Middle of the road' (Riahi et al., 2017) estimates, have been taken for this scenario regarding population and GDP expectations. No structural change is performed through the A Matrix. Also, income distribution continues a slow shift towards capital compensation to the detriment of labour share, with no working time reduction policies, although it follows a slow decrease based on historical trends. Productivity growth tends to be lower, as do the change in the energy mix efforts, the increase in energy productivity and the TPES reduction (following REF16).

2) A 'Green Growth' scenario, with an ambitious energy transition in the energy mix, high energy efficiency gains leading to a TPES reduction (EUCO33) combined with relatively higher productivity growth (getting back to the historical average prior to the Eurozone crisis), a transition to an efficient economic structure and high population and GDP expectations growth (according to SSP1, the 'Sustainability' narrative). Income distribution provides a relative increase in the labour share, but no WTR policy is implemented.

3) In the 'Post-Growth' scenario, the energy mix transition is equal to 'Green Growth', but with slightly higher efficiency ${ }^{6}$ and a more ambitious TPES reduction (EUCO40). However, unlike the other scenarios, GDP expectations and population growth are lower, primary income distribution shifts greatly to labour and a WTR policy is implemented. Simultaneously, a structural change that encourages the less energy and more labour intensive sectors (and discourages to the opposite ones) via the A matrix is operated (see Appendix B). In order to carry this out, the amount of inputs purchased by all the sectors from different industries is increased or decreased (modifying by rows the technical coefficients of the targeted industries). For instance, agriculture, light industries, electricity and electrical equipment, reparations and retail trade except motor vehicles, health, education, social work and public administration have all been increased; whereas mining, refineries, transport, finance

${ }^{6}$ We assume that technology-based energy efficiency gains still operate in this scenario, but with a higher effort done regarding demand-management policies, such as building retrofitting, urban planning, public transport, etc. 
and the retail trade of motor vehicles have been reduced. Also, the efficiency of the electricity sector is improved by reducing the amount of inputs it requires to produce its output. These changes result in an overall reduction of the intermediate consumption's weight on total production.

All these scenarios assume that the World is subject to energy limits according to MEDEAS-W simulations and the same 'Best guess' approach to select the primary energy extraction capacity of the EU28.

\section{Results}

Because one of the objectives of this article is to compare the MEDEAS results with the ER50 and EUCO scenarios, the variables chosen to be shown are those considered important in this respect. These are GDP and employment, as relevant socioeconomic variables, and CO2eq emissions as the main climate outcome (Figure 25 for the sequential and Figure 26 for the storyline scenarios). In addition, such energy-related outcomes as the import dependency rate (Net Imports of Primary Energy/TPES) and the RER share on TPES are included (Table 1).

i/ The first relevant result that can be noticed is that as soon as the TPES reduction is imposed, all the socioeconomic outcomes are worse compared to the Base scenario, but obviously better in terms of climate and energy goals. This suggests a conflict between the combination of environmental and socioeconomic objectives that can be nuanced thanks to different interventions. Through the ER50 scenarios, we can see that the REF16 scenario is able to achieve climate and energy outcomes similar to EUCO 27 and 33, but at a high socioeconomic cost. On the other hand, EUCO40 is the closest to the ER50 climate goals by 2050 with a $67 \%$ reduction with respect to 2010 (72\% compared to 1990), but with similar socioeconomic results to REF16. The import dependency declines and the RER increases as the restrictions to the use of NRER are higher. In fact, both indicators are better in our forecasts compared to the European Union's estimates (Table 1). Nevertheless, again, this is achieved by incurring low employment outcomes and GDP stagnation (EUCO27 and 33) or collapse (REF16 and EUCO40), and these are only the results of applying the TPES restriction scenarios to the base model.

ii/ World Limits (WoLim): We can distinguish a short-term and a long-term effect. During the first simulation years, the export-intensive sectors reduce their sales. However, because the economy is still growing -though slowly- consumption (c) and investment (gfcf) are able to compensate for the impact of the weakening of sales abroad. Nevertheless, as a consequence of the energy constraint that is assumed, the domestic impulse after 2030 cannot 
sustain aggregate demand any longer. Consequently, GDP declines, as does the level of employment. Paradoxically, the fall of both indicators after imposing the world limits is less severe in all the scenarios. The fact that the exporting activities are more energy-intensive could explain this counter-intuitive effect. When these sectors' production is capped by the deterioration of the global economic context, energy demand decreases, releasing the economy-wide growth potential. This interesting outcome could unveil the prevalence of biophysical constraints to the socioeconomic ones. Furthermore, the overall reduction in commerce also leads to the shrinking of the dependency on imports and a small reduction in the GHG emissions decline as the RER share increases.

iii/ Lower productivity growth (LowProd): as long as it is imposed under primary energy use restrictions, it has no significant effects on GDP, GHG emissions, or energy-related outcomes. It does not matter how productive labour is if the energy inflows required from the productive processes are not delivered. This is the same as stating that a higher productivity growth would not improve the economic situation, given the energy constraints. In fact, under this context, a lower increase in productivity would contribute to significantly enhance the employment outcomes, as can be seen in Figure 6. Despite the positive effect on employment, it is still not enough to steer it closer to the Base, where full-employment is attained. The role of productivity is discussed in section 4. 
Figure 6. Sequential scenarios for Energy Roadmap 2050 key variables.

Source: own elaboration
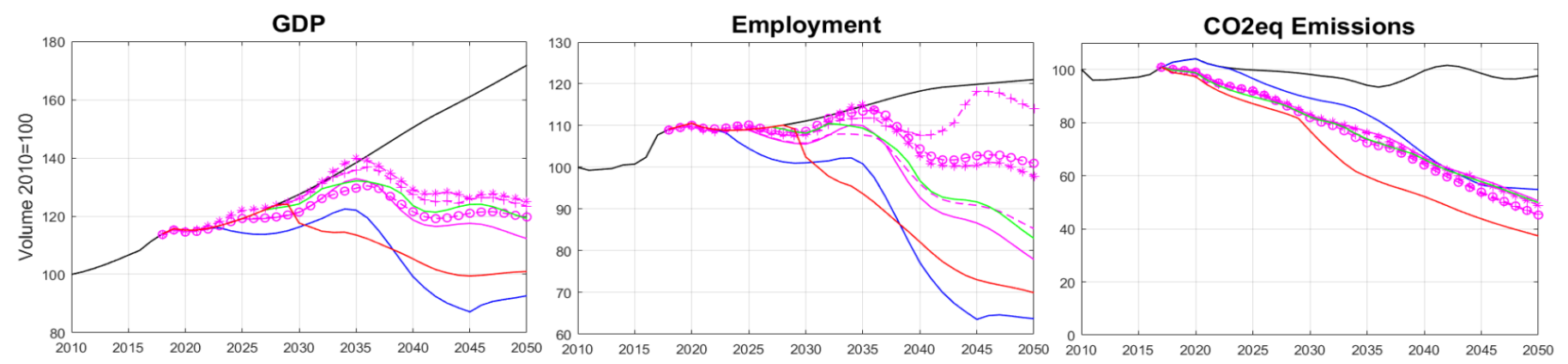

-Base - REF16 -EUCO27 ---EUCO27_WoLim - $\theta$-EUCO27_LowProd -*-EUCO27_SCh -+-EUCO27_Lab -EUCO33 —EUCO40
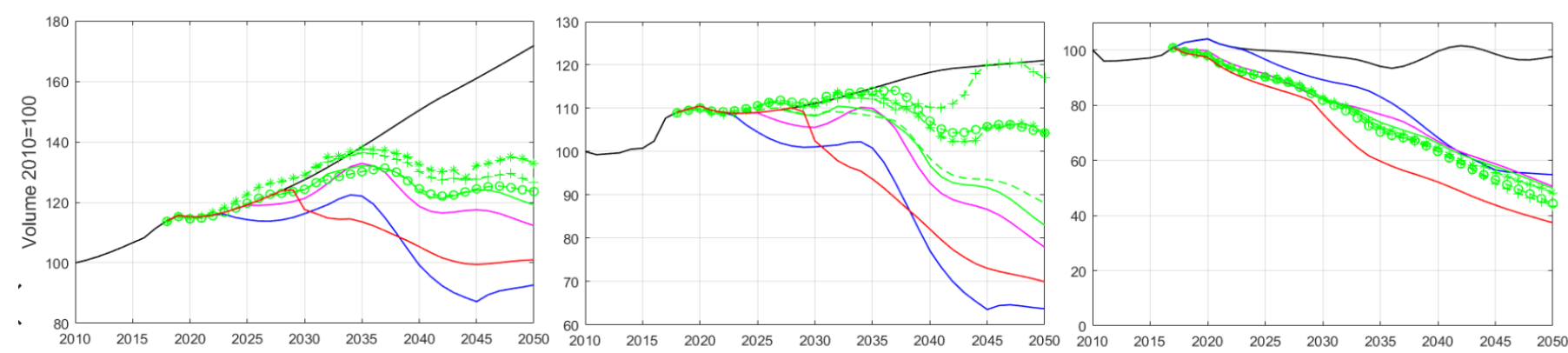

-Base - REF16 —EUCO27 —EUCO33 - --EUCO33_WoLim - - -EUCO33_LowProd - *-EUCO33_SCh - +-EUCO33_Lab —EUCO40
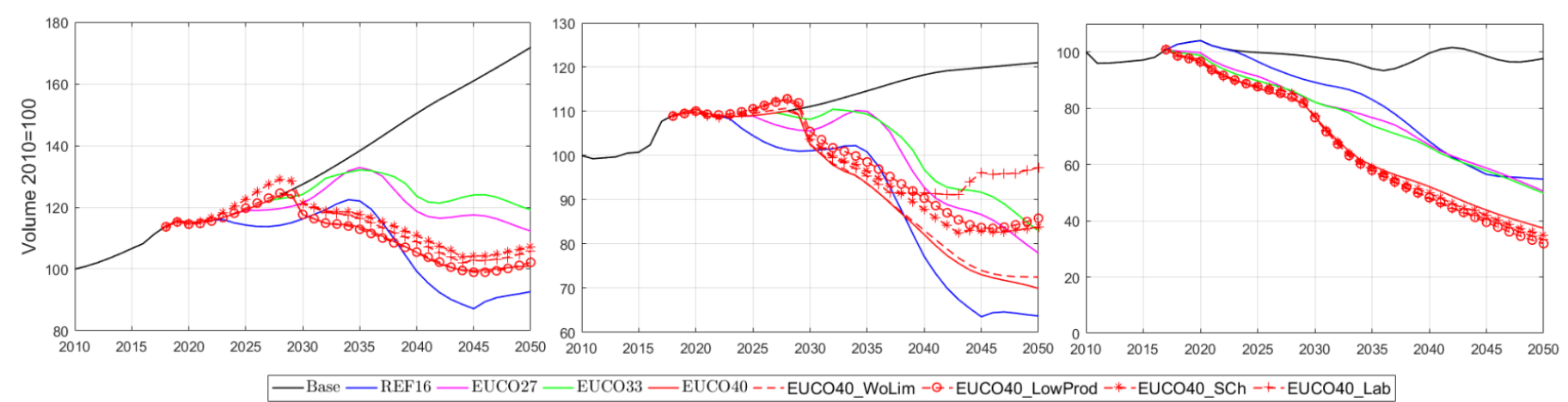
iv/ Structural change (SCh): by converging to the Germany's more efficient structure, a lower proportion of intermediate inputs $\left(z_{i j}\right)$ are required to produce the same value of output $\left(x_{j}\right)$, resulting in an overall reduction of $a_{i j}$, thus broadening the economy's capacity to produce value added $\left(g v a_{j}\right)$. Therefore, final demand is eventually stimulated, leading to an increase in GDP, production and employment. Nevertheless, this also results in higher energy demand in what could be seen as a sort of a 'rebound effect'. Thereby, the increased GDP also triggers thus, not offset by efficiency gains- a rise in GHG emissions and the dependency on imports.

v/ Pro-Labour policies (Lab): A working time reduction (WTR) policy is gradually implemented, reducing the $h p w$ by $14.28 \%$ (the equivalent reduction from $35 \mathrm{~h}$ to $30 \mathrm{~h}$ ) by the middle of the 2030s, before employment collapses. Simultaneously, there is an increase in the labour share -taken as a proxy variable of the labour bargaining power- in order to maintain the purchasing power of households that sustain aggregate demand during the gradual implementation of the policy, though GDP slightly declines. Employment rises in EUCO27 and EUCO33. However, the energy restriction is so severe in EUCO40 that not even the WTR policy is able to restore the level of employment. Together with the improvement in employment, it also corrects the increase in GHG emissions unleashed by the structural change, thus also achieving an enhancement of the climate goals.

As mentioned before, in addition to the sequential scenarios, a set of three coherent 'storylines' (Business as Usual, Green Growth and Post-Growth) have been assessed as scenarios, which are shown in Figure 7:

1) BAU: climate goals are met only after economic collapse. Because the efforts to install new renewables infrastructures are low, all the NRER demand cannot be met via domestic extraction and imports need to increase, leading to an energy shortage if the REF16 estimates are not to be trespassed; even considering the cautionary $25 \%$ buffer applied (see section 2.3). By 2030, the economy is no longer able to cope with the NRER restrictions given the absence of a credible energy mix transition. Despite the increase in the capital share, investment is not able to stimulate aggregate demand, given the containment of salaries and the energy shortage. Therefore, employment demand plummets. Despite the economy's downfall, the GHG emissions reduction by 2050 is higher than the Ref 16 and EUCO scenarios (2050 projections), both the estimations from the EU reports and MEDEAS simulations. 

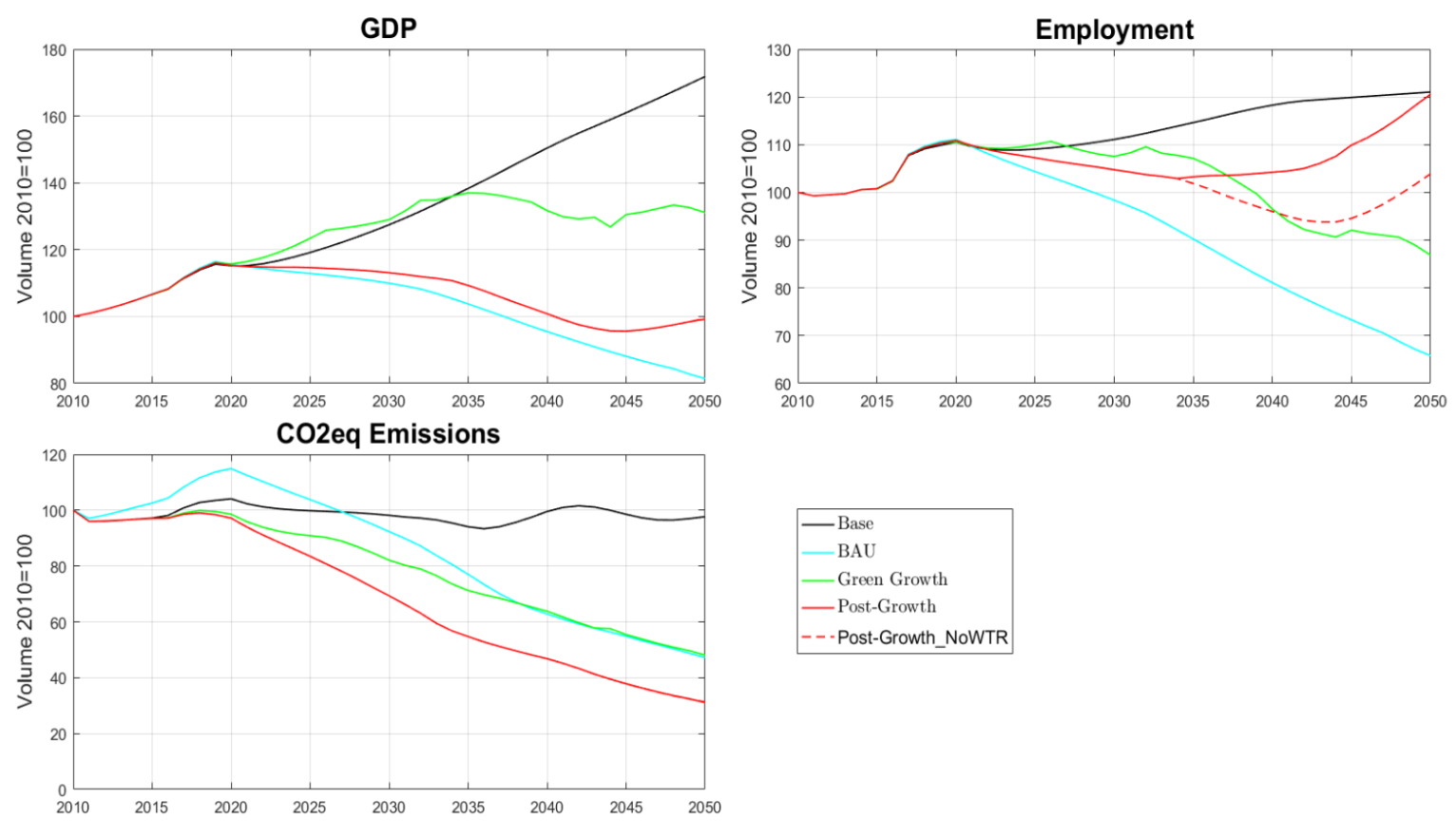

Figure 7. Combined Scenarios main results

Source: own elaboration.

2) Green Growth: technological change-represented by an intense increase in energy efficiency and the gradual transition towards a more efficient A matrix- and a shift in the energy mix reduce environmental pressures. Nevertheless, an increased productivity growth consistent with the scenario storyline, the higher GDP and population growth expectations impose a pressure on the energy system that hinders the energy transition. The high energy demand required to satisfy an increased aggregate demand -also bolstered by a rise in the labour share- at an early stage of the energy transition makes it difficult to deploy the new RER infrastructures on time. As a consequence, the RER share on TPES is similar to that in REF16, EUCO27 and EUCO33, leading to the noncompliance of GHG emissions reduction by 2050 . Nevertheless, due to the enhanced capacity of the economic system, GDP and employment values are better than in these scenarios, yet not enough to avoid economic downturn by 2035 and stagnation after 2040 .

3) Post-Growth: This scenario reduces the import dependency rate to $30 \%$, has the higher RER share on TPES (54\%) -apart from the collapse-led reduction in BAU-, higher employment rates and is the only scenario - except BASE- that barely meets climate goals: 24.7 with $2010=100$, i.e., $79 \%$ with respect to 1990 . On the negative side, GDP would be slightly lower than 2010, meaning that the EU28 would need to deal with a declining GDP soon if climate targets are to be met. An additional variant has been included (Post-Growth_noWTR) to isolate the effects of a rise in the labour share from the working time reduction policy under 
energy constraints. A reduction in the level of employment is observed in comparison to the scenario that includes the WTR policy. 
Table 1. Import Dependency, Renewables share on TPES, GDP, Employment and GHG emissions by Scenarios.

\begin{tabular}{|c|c|c|c|c|c|c|c|c|c|c|c|c|c|}
\hline & & \multicolumn{3}{|c|}{ Import Dependency (\%) } & \multicolumn{3}{|c|}{ RER share on TPES (\%) } & \multicolumn{2}{|c|}{ GDP $(2010=100)$} & \multicolumn{2}{|c|}{ Employment $(2010=100$} & \multicolumn{2}{|c|}{ GHG emissions $(2010=100)$} \\
\hline & & 2010 & 2030 & 2050 & 2010 & 2030 & 2050 & 2030 & 2050 & 2030 & 2050 & 2030 & 2050 \\
\hline \multirow{4}{*}{ Energy Roadmap 2050} & Ref 2016 & \multirow{24}{*}{50.2} & 56.6 & 57.6 & \multirow{24}{*}{11.4} & 9.7 & 23.6 & \multirow{4}{*}{129.4} & 174.7 & & 76.5 & 61.72 \\
\hline & EUCO+27 & & 54.3 & $58.4^{*}$ & & \multirow{3}{*}{19.6} & \multirow{3}{*}{$27.8^{*}$} & & \multirow{3}{*}{$158.8^{*}$} & & & 70.0 & $40.0^{*}$ \\
\hline & EUCO+33 & & 52.6 & $55.0^{*}$ & & & & & & & & 67.3 & $34.6^{*}$ \\
\hline & EUCO+40 & & 51.8 & $53.4^{*}$ & & & & & & & & 62.4 & $24.8^{*}$ \\
\hline \multirow{20}{*}{$\begin{array}{l}\text { MEDEAS - Europe } \\
\text { estimates }\end{array}$} & Base & & 50.8 & 55.3 & & 20.0 & 29.7 & 127.5 & 171.8 & 111.1 & 121.0 & 98.2 & 97.7 \\
\hline & REF16 & & 49.3 & 40.0 & & 22.7 & 42.4 & 116.2 & 92.7 & 101.1 & 63.7 & 89.2 & 54.8 \\
\hline & EUCO27 & & 47.7 & 39.6 & & 23.8 & 42.3 & 121.3 & 112.3 & 105.6 & 77.9 & 82.1 & 50.5 \\
\hline & WoLim & & 47.3 & 37.9 & & 24.2 & 44.2 & 121.4 & 119.7 & 105.8 & 85.3 & 81.9 & 45.2 \\
\hline & Prod & & 47.4 & 37.9 & & 24.2 & 44.2 & 121.4 & 119.7 & 108.7 & 101.0 & 81.9 & 45.2 \\
\hline & SCh & & 47.8 & 39.9 & & 23.9 & 42.3 & 126.0 & 125.0 & 107.8 & 97.9 & 82.9 & 48.9 \\
\hline & Lab & & 47.8 & 38.5 & & 24.2 & 43.6 & 126.0 & 123.5 & 107.8 & 114.0 & 82.9 & 45.4 \\
\hline & EUCO33 & & 47.8 & 39.4 & & 24.0 & 42.8 & 124.2 & 119.2 & 108.2 & 83.0 & 82.2 & 49.8 \\
\hline & WoLim & & 47.9 & 38.0 & & 24.0 & 44.5 & 124.3 & 123.6 & 108.4 & 88.2 & 81.8 & 44.4 \\
\hline & Prod & & 47.8 & 38.1 & & 24.1 & 44.5 & 124.3 & 123.6 & 111.3 & 104.3 & 81.8 & 44.4 \\
\hline & SCh & & 48.0 & 40.1 & & 24.0 & 42.4 & 129.0 & 132.8 & 110.4 & 104.2 & 82.7 & 48.3 \\
\hline & Lab & & 48.0 & 37.8 & & 24.0 & 44.6 & 129.0 & 126.7 & 110.4 & 117.0 & 82.7 & 43.6 \\
\hline & EUCO40 & & 46.1 & 30.7 & & 25.2 & 50.4 & 117.6 & 101.0 & 102.5 & 70.0 & 76.9 & 37.3 \\
\hline & WoLim & & 47.2 & 30.6 & & 25.3 & 51.8 & 117.7 & 102.2 & 102.7 & 72.5 & 76.7 & 31.9 \\
\hline & Prod & & 47.2 & 30.4 & & 25.3 & 51.9 & 117.7 & 102.2 & 105.4 & 85.8 & 76.7 & 31.9 \\
\hline & SCh & & 47.5 & 30.8 & & 25.1 & 50.5 & 121.1 & 107.3 & 103.7 & 83.9 & 77.2 & 34.8 \\
\hline & Lab & & 47.5 & 30.8 & & 25.1 & 50.4 & 121.1 & 105.8 & 103.7 & 97.3 & 77.2 & 33.4 \\
\hline & BAU & & 46.0 & 29.6 & & 22.0 & 57.4 & 110.0 & 81.5 & 98.4 & 65.8 & 92.4 & 47.2 \\
\hline & Green Growth & & 48.8 & 40.4 & & 23.6 & 42.2 & 129.0 & 131.1 & 107.5 & 86.8 & 82.1 & 48.1 \\
\hline & Post-Growth & & 45.4 & 30.0 & & 26.1 & 54.6 & 113.1 & 99.2 & 104.8 & 120.6 & 69.3 & 31.1 \\
\hline
\end{tabular}

Source: own elaboration. *Linear projection. 


\section{Discussion}

Modelling complex systems means taking uncertainty and complexity into account. The scenarios-based analysis allows uncertainty to be dealt with transparently. In fact, the sequential scenarios' outcomes can be seen as the likely pathways under different policy or scenario assumptions. Whereas it is common in the literature to introduce different variants -or scenariosin order to assess their marginal effect on the results, in this article, these variants are cumulative, which would offer a more complete picture. There are two reasons why we consider this a more appropriate approach. Firstly, because in the real world, policies and structural conditioners -the landscape in transitions terminology (Geels, 2002)- tend to operate simultaneously and not individually. Secondly, because dominance hierarchies can thus be revealed between the different hypotheses, as described below. These scenarios were set in the first place because this paper aims to test the effects of energy restrictions on the economy.

On the other hand, system dynamics is an appropriate methodology to deal with complex systems. It is able to allow the examination of the propagation of disturbances in the system, taking feedback loops, time lags and stock-flow relationships into account. This also fits well with the ecological economics theoretical framework (Constanza and And, 1997; Farley and Daly, 2003) whereby, in a planet with finite stocks of resources, the socioeconomic system is limited to the boundaries imposed by the environment. Its metabolic standpoint, in turn, enables an understanding of sustainability transitions aligned with the socio-metabolic approach (Krausmann et al., 2008; Fischer-Kowalski, 2011). According to this approach, transitions to sustainability are bounded to 'the energy system a society depends upon', subject to lock-in situations or system collapse (Tainter, 1988, 2011), or tipping points in earth systems (Lenton et al., 2008). MEDEAS is able to take this into consideration, fully integrating the economy and the biophysical systems. Models and policymakers should not disregard the two-way, subordinated relationship between the socioeconomic system and the environment.

\subsection{An ecological macroeconomics contribution to Post-Keynesian theory}

Conventional economics pictures environment-economy relationships as a source of positive (environmental services, contingent valuation, etc.) and negative (pollution, damage to health, etc.) externalities transversal to the circular flow of income. Ecological Economics, on the other hand, depicts the economic and social processes as embedded in and constrained by the natural systems of which they are subsystems. Therefore, we argue that the Ecological Economics foundations provide an insightful contribution to ecological macroeconomics and particularly to the Post-Keynesian theory of employment and growth. 
Indeed, ecological macroeconomics models (Rezai, Taylor and Mechler, 2013; Taylor, Rezai and Foley, 2016; Hardt and O'Neill, 2017) have contributed to that body of literature increasingly grounded in Keynesian and Post-Keynesian Economics (PKE) (Kaldor, 1957; Lavoie, 2015; Cahen-Fourot and Lavoie, 2016), and simulation, demand-led models have proven their worth in Integrated Assessment Modelling (Scrieciu, Rezai and Mechler, 2013).

The MEDEAS Economy module and Employment sub-module inspiration in PKE can be summarised in the three following characteristics: $i$ / the level of employment is determined by the aggregate demand -and based on IOA, i.e., the complementarity of productive factors; ii/ labour demand is not determined by wages but, if anything, aggregate demand is a positive function of wages; iii/ labour demand is not systematically converging towards equilibrium with labour supply: involuntary unemployment is considered and technological unemployment play an important role. All of them are consistent with a Kaleckian approach to employment and subject to revision when analysed under biophysical constraints.

Although the model is built according to these principles, in the context of energy restrictions, a rise in wages could lose its effectiveness to increase the labour demand. As can be seen in the Post-Growth_noWTR scenario (Figure 7), employment reaches a lower level despite the higher wages linked to an increase in the labour share. Figure 8 represents a (for the sake of the argument) simplified version of the Kaleckian employment model, inspired in Lavoie (2014). According to this model, the labour demand is a positive function of the real wages, as an increase in them represents a stimulus to aggregate demand. Therefore, a rise in those real wages $(w / p)$, from $(\mathrm{w} / \mathrm{p})_{0}$ to $(\mathrm{w} / \mathrm{p})_{1}$, would imply a movement up along the labour demand curve, resulting in an increase in the level of employment from $\mathrm{L}_{0}$ to $\mathrm{L}_{1}$. However, beyond full employment $\left(\mathrm{L}_{\mathrm{FE}}\right)$, an increase in real wages above (w/p) FE would be ineffective.

What the results of this article suggest is that the energy supply constraints could act as a reducer of the full capacity of the economy, regardless of the labour supply, i.e., even below the level of full employment. As such, the same real wage increase would only be able to increase the level of employment from $\mathrm{L}_{0}$ to $\mathrm{L}_{2}$, capping real wages up to a maximum of $(\mathrm{w} / \mathrm{p})_{2}$. Thus, the environment would be a determinant of the economy's boundaries, just as Ecological Economics states. Accordingly, the sustainability approach of this theoretical framework would be fully operating in this extended model, as energy would be acting as an absolute restriction, not a relative one, since it is not possible to avert its consequences by substituting energy with neither manufactured capital (through investments increasing aggregate demand) nor labour, as an aggregate neoclassical production function would allow. Rather, the complementarity of the 
energy inputs to produce the economic throughput would drive the economy's full potential leftwards in Figure 8, i.e. reducing it.

Hence, a paradox emerges, since the initial status as a wage-led economy (Bhaduri, 2007; Lavoie and Stockhammer, 2013), i.e., wages being the main driver of the aggregate demand increases instead of profits, is rejected after imposing energy constraints. Moreover, as the Green Growth scenario shows, not even an exogenous increase in aggregate demand would be able to maintain the level of employment, as it would face the same reduced full capacity. Nevertheless, the application of a working time reduction (WTR) policy could help the level of employment to rise. In effect, the results of the pro-labour policies (Lab) in section 3 show a negligible response on GDP, which may suggest a lowering of the full capacity threshold of the economy. PKE states that a working time reduction policy, to be successful in increasing the level of employment, must raise wages at the same or a higher proportion than productivity growth in order to maintain aggregate demand (Nell, 2005). In Figure 8, once in $\mathrm{L}_{2}$, a WTR policy could potentially avoid the energy-restricted full capacity and get back to $L_{1}$, as long as salaries increase to $(w / p)_{1}$. Conversely, if salaries still remain at $(\mathrm{w} / \mathrm{p})_{2}$, employment would not be able to recover, as the effective demand would not have been stimulated.

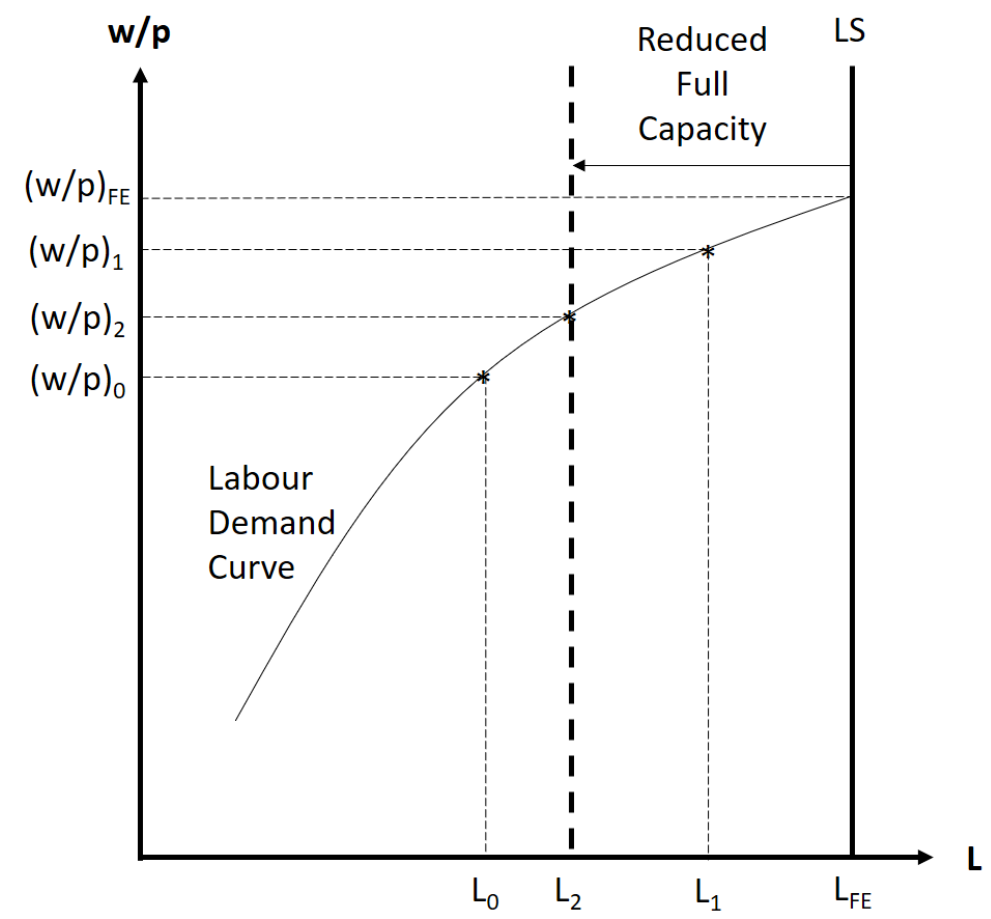

Figure 8. Kaleckian employment model extended with energy supply constraints. Source: own elaboration.

Therefore, it could be expected that expanding the level of employment becomes increasingly difficult if energy use is restricted. However, according to our results, a WTR policy could contribute to increasing the level of employment under energy constraints if a considerable 
socioeconomic change is undertaken, such as the one defined in the Post-Growth scenario. Moreover, a higher labour share, combined with WTR, may have the ability to reinforce disposable income and reduce income inequality.

Regarding the role of productivity and technological unemployment, the MEDEAS approach can also supplement PKE with new insights. According to the Kaleckian employment model, an increase in productivity can result in a reduction in the level of employment if it is not accompanied by a greater increase in salaries. In fact, because salaries have lost their ability to expand aggregate demand under energy constraints, higher productivity growth is very likely to reduce the level of employment. Moreover, productivity plays a contradictory role in modern capitalist economies in what Jackson and Victor (2011) called the 'productivity trap'. Certainly, in a profit-seeking economy, where capital owners need to compete in order to avoid an interruption of the accumulation process, there is a natural incentive to increase productivity so their labour costs are reduced.

On the other hand, productivity growth also implies a reduction in the labour requirements to produce the same output, as well as a constraint to aggregate demand if wages do not increase at least at the same rate. The authors explore the potential to maintain jobs while reducing carbon emissions by applying a working time reduction policy and an industrial policy oriented towards favouring the more labour-intensive sectors in the UK. Our results in the Post-Growth scenario would confirm that study, now generalized to the EU28 and even forecasting a potential increase in employment. In fact, a shift towards a low-productivity growth regime is a phenomenon that is already taking place: a reduction in overall productivity growth has been observed since the late 1970s in the OECD countries (this would also justify the LowProd assumption and its integration in the BAU scenario). Given the historically tight link between access to high-quality energy resources and productivity growth, in a context of lower energy use and the transition to less power density sources, the fall in productivity growth may continue (Jackson, 2019).

As captured by the MEDEAS labour feedback, if the labour requirements to increase GDP are higher than the available labour force, then GDP growth will be lower than expected. Therefore, population or productivity growth can contribute to easing this pressure. Considering the ageing of the population, as well as the decline in population growth rates, the two most likely options for the EU in the future may be the following: Firstly, increasing productivity sufficiently to avoid this situation, but not by enough to escape the 'productivity trap'. Then again, as long as the full potential of the economy may be capped by the energy restrictions -as shown in our results-, labour productivity growth may be ineffective to reinforce GDP growth. Secondly, it could actually be more likely, since productivity growth rates are steadily falling, as is already 
happening in particular EU economies, for instance Germany, where there are calls to increase its labour force once the stagnation of productivity growth has completely settled in. Of course, this may well be unevenly distributed across the EU countries.

\subsection{A realistic methodology to assess energy transition scenarios.}

The set of models used by the European Commission to develop the REF16 scenario are interconnected, but only the economy is left as a 'framework assumption', based on the Computable General Equilibrium (CGE) model GEM-E3. The EUCO scenarios were created using PRIMES with the Ref2016 as the starting point and, after that, two other modelling exercises were undertaken to assess their potential macroeconomic impacts. The GEM-E3 (E3MLab and IIASA, 2016) model shows an improvement of both GDP and employment as energy restrictions get harsher, when financing is loan-based instead of based on self-financing. The E3ME (Pollitt, 2016) modelling describes a similar situation, with GDP 2.2\%-4.4\% and employment $1.4 \%-2.1 \%$ higher in the EUCO+40 as compared to the EUCO+27 by 2030. However, MEDEAS follows a different methodology, whereby not only the environment is influenced by the economy, but the environment also conditions the economy. In fact, the conditioning power of the environment over the economy is so strong that some policies lose all or part of their capacity under energy constraints, as explained before.

The lack of integration of the different components of the system in IAMs could lead to the overestimation of the capability of the economy to absorb large energy use reductions, as well as huge energy efficiency gains. For instance, the set of models used by the European Union presents a unidirectional link between the economy and the environment. According to this, the economy is virtually autonomous and the environment plays a passive role as a same-level subsystem that only receives impacts from the economy. To the best of our knowledge, this is very common in IAM, which may be leading to unrealistic outcomes that could mislead the policymakers' future decisions.

Once this is taken into consideration, as can be seen in section 3, the stricter the TPES reduction, the more difficult it would be for the economy to maintain macroeconomic stability. As a result, all the scenarios simulated present a fundamental conflict between environmental and social objectives. The economic downturn that would occur by 2030-2035 has to do with a projected decrease of the coal use and natural gas net imports quicker than the economy's capability to deal with it. Conveniently, the ER2050 targets for oil are not too tight -which may be the reason why the scenarios struggle to meet the climate goals- but very harsh for natural gas. The inability of the economy to cope with these energy restrictions is twofold: i/ the inability of 
energy efficiency to produce a net reduction in energy use, once accounted with efficiency gains; and ii/ systemic rigidities to reduce the dependency on certain fossil fuels.

Regarding energy efficiency, not even applying major gains does the economy receive sufficient energy inflows and, therefore, a slowdown or even a downturn of GDP occurs. It is important to note that the decline of GDP could have been steeper should the climate change damage function and/or the adaptive GDP growth expectations -as the decline would have reinforced depressed expectations- had been enabled. Furthermore, because employment is determined by aggregate demand, the level of employment falls in the reduced energy consumption scenarios. The basic hypothesis underlying conventional models is that energy consumption will be reduced by as much as energy efficiency grows. This paradigm underestimates the presence of rebound effects (Blake, 2005; Polimeni et al., 2015) and energy availability limits. In MEDEAS, the rebound effect is implicitly considered. Because energy scarcity hinders economic growth, the higher the energy efficiency gains are, the longer the accumulation progress can last. Therefore, energy efficiency gains increase the potential aggregate demand, which eventually leads to higher energy consumption. This is what explains the ability to grow faster in the EUCO and Green growth scenarios as compared to REF16 at an early stage. But then, the intensified pressure on natural resources, triggered by the higher demand, interrupts economic growth. This may show the importance of the adequate accountability of both the direct and indirect effects of the necessary energy efficiency targets.

Concerning systemic rigidities, the sectoral structure of MEDEAS allows acknowledging for the inherent difficulties of some industries to reduce their energy resources requirements. For instance, the hurdle to phase-out oil in the aviation sector or coal in the steel and cement industries is deep-rooted. MEDEAS is a granular framework based on Input-Output Analysis, that enables the emergence of situations that would remain hidden in aggregated models and their spill-over effects on all industries. Thus, we argue that given these rigidities, some industries need to adapt in advance, even more that the others, to an eventual lack of energy source across all the supplychain, i.e. not only the abovementioned sectors have to reduce their dependency on NRER -if possible at all- but industries depending on these industries like tourism, construction or all manufacturing industries relying on steel. By all means, adaptation in all sectors would require an absolute reduction in energy use that could be faced by energy efficiency at the device level, but especially by demand-side management policies, given the proximity to the thermodynamic limits to the former in advanced economies (Groscurth, Kümmel and Van Gool, 1989; Ayres, 2007; Brockway et al., 2015) and the potential effectivity of the latter (Creutzig et al., 2016, 2018). However, on top of that, industrial policy has revealed as an utterly relevant tool of sectoral adaptation to eventual energy scarcity, despite it has been ruled out in practice over the last few 
decades. Therefore, favouring less energy-intensive sectors, along with the more labour-intensive sectors, in the Post-Growth scenario (see section 3) was crucial to reconciling environmental and social objectives.

Finally, the results of our modelling approach would entail a rebuttal of the decoupling and green growth literature, particularly to the EU's prospects for the ER2050. Moreover, this would even deny the possibility of long-lasting weak decoupling in an advanced economy like the EU's. This decoupling would be possible during a mid-term period (until 2030-2035) but would not last enough to achieve the climate goals to meet the IPCC recommendations. The conflict is well represented by the Green growth scenario, which also poses a challenging paradox: despite the great efforts to unfold a renewable energy transition, along with rapid energy efficiency gains, would require massive energy inflows that, at the early stage of the transition, must be provided substantially by NRER. This fact is especially intense under a high GDP and productivity growth regime. Not even an industrial policy aimed at converging with a modern, efficient, emissions-reducer structure like Germany's is able to offset this tendency. As a result, the import dependency in the Green growth scenario is similar to that in the MEDEAS REF16 estimate (40\%), yet much lower than the EU Ref2016 estimate by 2050 (56\%). Similarly, the GHG emissions do not decrease enough to meet the climate goals (55\% with respect to 2010 , i.e., $61 \%$ over 1990). Moreover, this scenario could not avoid a decrease in employment, which could potentially be corrected by WTR policy. Conversely, only the Post-Growth scenario would be able to address the climate challenge.

The MEDEAS model is continuously evolving in order to improve its capabilities. Further developments aimed at an endogeneisation of the A Matrix evolution, the inclusion of demand management policies, the full integration of the economic cycle-linked to productivity, the level of employment and income distribution- and the addition of financial flows -through a stock-flow consistent approach (Lavoie, 2012)- are some of the developments that are expected.

\section{Conclusions and Policy implications}

The energy transition that the European Union is decided to undertake, described in its Energy Roadmap 2050, is not without its challenges. In order to cope with them, an important and serious modelling effort has been done. At an early stage of the Roadmap (in 2013), the European Union unveiled a first report anticipating the main results to be expected under different hypotheses. The first 'Reference' scenario, i.e., expressing current trends without energy transition objectives after 2020, forecasted a net increase in energy consumption by 2050 . However, the Eurozone crisis changed the 'current trends' and, after that, a new 'Reference' 
scenario was released in 2016. In addition, the EUCO scenarios were also released in order to explore further energy reduction and more ambitious transition pathways. In this new version, following the new 'current trends', the 'Reference' scenario forecasted a net reduction of energy consumption in 2050. However, only one year later, energy consumption resumed its tendency to grow. The European Union's scenarios predict that the energy transition will boost economic growth and employment creation. However, the results obtained from MEDEAS-Europe are suggesting that such energy use reductions may well be harming key socioeconomic indicators in the absence of further policies.

Insufficient integration of the economic system, and the resources that the economy rely on, can lead to modelling results that are not able to account for the limits that the former imposes on the latter. Should this be disregarded, the one-way relationship from the economy to society and the environment, inevitably leads to socioeconomic outputs being improved as energy use is downsized. The optimization hypothesis as the cornerstone of the economic process guarantees equilibrium - in the long-run in the worst case- and therefore full employment, while continued economic growth drives employment unequivocally up. MEDEAS-Europe contributes to filling this gap by adopting an ecological economics approach, whereby the economy is a subsystem of the biophysical system and the society. Thus, a deficient energy supply to what is required from the economy to maintain a certain GDP growth would reduce the economy's full capacity. As a consequence, this investigation shows that, despite the high energy efficiency gains applied to all the Energy Roadmap scenarios, the forecasted socioeconomic outputs are unlikely to be achieved. Moreover, the climate goals would only be reached at great socioeconomic costs. In fact, under reduced energy use scenarios, monetary demand stimulus may no longer be effective to sustain employment creation -as the Keynesian and Post-Keynesian literature states. In this context, the inherent trend of the market-based economic systems to increase labour productivity would potentially deepen employment destruction.

In general terms, all the MEDEAS-EU28 scenarios present a trend that implies a reduction in the dependence on imports - except Base-, the GHG emissions and an increase in the RER share. However, in REF16, this has more to do with NRER depletion and reduced capability to import, and not due to an adequate energy transition. EUCO40 is unable to cope with such a steep energy use reduction while avoiding economic downturn, which eventually leads to the reduction of dependency and environmental impacts. It can be seen that the ER2050 might be overestimating GDP growth in all their scenarios and, as a consequence, without any intervention to stimulate employment, labour demand would strongly decline. Structural change towards an increased economic efficiency would be able to 'buy time' in terms of GDP growth, but without industrial policy aimed at decreasing the importance of the energy-intensive sectors and 
increasing the less-energy intensive ones, this would lead to additional environmental impacts. In fact, if the EUCO scenarios are projected to 2050, this effect would be ineffective after the 2030s. Therefore, pro-labour policies may be required to sustain employment along with meeting the environmental goals.

As a result of the above, only a self-defined Post-Growth scenario is able to cope with the shift to renewables and the energy use reduction transition, while maintaining employment and achieving a substantial emissions reduction (70\%). This would call into question the feasibility of policy agendas committing to net zero by 2040, without a detailed socioeconomic shift plan. The results attained in the PG scenario are caused by the structural change steering the economy towards labour-intensive and less energy-intensive sectors, as well as a reduction in the GDP growth expectations. In order to compensate for this, an increase in salaries accompanying a working time reduction (WTR) policy lets employment recover. This highlights the importance of the Post-Keynesian standpoint, whereby a WTR policy should be aligned with a wage increase that outpaces productivity growth if employment is to be maintained. Actually, reducing the proportion of intermediate inputs to produce economic inputs could contribute to reducing the material and energy inputs required from the economy. However, if these pro-labour policies are not undertaken, employment would not be likely to react. For instance, an increase in the labour bargaining power (or the labour share) could avert the appropriation of the increase in income since gross value added has been broadened by reducing the intermediate consumption to produce one unit of output- by the capital-owners, which could lead to higher inequality and reduced aggregate demand -given that salary-earners are more keen on expending, proportionally, than capital-owners. Thus, this could contribute to the main challenge of this narrative: the decoupling of human well-being from economic growth.

\section{Acknowledgements}

We are grateful for the support in the elaboration of this article from the European project H2020-LCE-2015-2 (691287) Guiding European Policy toward a low-carbon economy. Modelling Energy System Development under Environmental and Socioeconomic constraints (MEDEAS). We are thankful as well for the support of MODESLOW project: MODElling and Simulation of scenarios towards a LOW-carbon transition: The Spanish case). A Spanish national research project (ECO2017-85110-R) funded under the Spanish National Research, Development and Innovation Program (Ministry of Economy and Innovation, Spain). We are thankful for the work developed within the Research Group on Energy, Economy and System Dynamics. We would also like to express our gratitude to the reviewers for their valuable comments. 


\section{References}

Antal, M. (2018) 'Post-growth strategies can be more feasible than techno-fixes: Focus on working time', The Anthropocene Review, p. 2053019618794212. doi: $10.1177 / 2053019618794212$.

Ayres, R. U. (2007) 'On the practical limits to substitution', Ecological Economics. Elsevier, 61(1), pp. 115-128. doi: 10.1016/J.ECOLECON.2006.02.011.

Bhaduri, A. (2007) 'On the dynamics of profit-led and wage-led growth', Cambridge Journal of Economics. Narnia, 32(1), pp. 147-160. doi: 10.1093/cje/bem012.

Bhaduri, A. and Marglin, S. (1990) 'Unemployment and the real wage: the economic basis for contesting political ideologies', Cambridge Journal of Economics. Oxford University Press, pp. 375-393. doi: 10.2307/23598376.

Blake, A. (2005) ‘Jevons’ paradox', Ecological Economics, 54, pp. 9-21.

De Blas, I. et al. (2018) European Model: MEDEAS Model and IOA implementation at European geographical level. Barcelona, Spain. Available at: http://medeas.eu/system/files/documentation/files/Deliverable 4.1 \%28D13\%29_Global Model.pdf.

Bowen, A. and Hepburn, C. J. (2012) Prosperity with Growth: Economic Growth, Climate Change and Environmental Limits. Rochester, NY. Available at: https://papers.ssrn.com/abstract=2575804 (Accessed: 17 April 2018).

Boyer, G. R. and Smith, R. S. (2001) 'The Development of the Neoclassical Tradition in Labor Economics', ILR Review, 54(2), pp. 199-223. doi: 10.1177/001979390105400201.

Brand-Correa, L. I. et al. (2017) 'Developing an Input-Output Based Method to Estimate a National-Level Energy Return on Investment (EROI)', Energies. MDPI, Open Access Journal, 10(4), pp. 1-21. Available at: https://ideas.repec.org/a/gam/jeners/v10y2017i4p534-d95815.html (Accessed: 10 
December 2019).

Brockway, P. E. et al. (2015) 'Understanding China's past and future energy demand: An exergy efficiency and decomposition analysis', Applied Energy. Elsevier, 155, pp. 892-903. doi: 10.1016/J.APENERGY.2015.05.082.

Brockway, P. E. et al. (2019) 'Estimation of global final-stage energy-return-oninvestment for fossil fuels with comparison to renewable energy sources', Nature Energy. Nature Publishing Group, 4(7), pp. 612-621. doi: 10.1038/s41560-019-0425-z.

Cahen-Fourot, L. and Lavoie, M. (2016) 'Ecological monetary economics: A postKeynesian critique', Ecological Economics. Elsevier, 126, pp. 163-168. doi: 10.1016/J.ECOLECON.2016.03.007.

Cambridge Econometrics (2013) Employment Effects of selected scenarios from the Energy roadmap 2050. Final report for the European Commission. Cambridge, UK. Available at: https://ec.europa.eu/energy/sites/ener/files/documents/2013_report_employment_effects _roadmap_2050_1.pdf.

Capellán-Pérez, I. et al. (2017) Global Model: MEDEAS- World Model and IOA implementation at global geographical level. Available at: https://www.medeas.eu/system/files/documentation/files/Deliverable \%28D13\%29_Global Model.pdf.

Capellán-Pérez, I. et al. (2020) 'MEDEAS: A new modeling framework integrating global biophysical and socioeconomic constraints', Energy and Environmental Science. Royal Society of Chemistry, pp. 986-1017. doi: $10.1039 / \mathrm{c} 9 \mathrm{ee} 02627 \mathrm{~d}$.

Capellán-Pérez, Í. (2016) Development and Application of Environmental Integrated Assessment Modelling towards Sustainability. University of País Vasco.

Constanza, R. and And, C. P. (1997) The development of Ecological Economics. Cheltenham: Edward Elgar. 
Creutzig, F. et al. (2016) 'Beyond Technology: Demand-Side Solutions for Climate Change Mitigation', Annual Review of Environment and Resources, 41(1), pp. 173-198. doi: 10.1146/annurev-environ-110615-085428.

Creutzig, F. et al. (2018) 'Towards demand-side solutions for mitigating climate change', Nature Climate Change. Nature Publishing Group, 8(4), pp. 260-263. doi: 10.1038/s41558-018-0121-1.

Csereklyei, Z. and Stern, D. I. (2015) 'Global energy use: Decoupling or convergence?', Energy Economics, 51, pp. 633-641. doi: 10.1016/j.eneco.2015.08.029.

D'Alessandro, S. et al. (2020) 'Feasible alternatives to green growth', Nature Sustainability. Nature Research, 3(4), pp. 329-335. doi: 10.1038/s41893-020-0484-y.

Dietzenbacher, E. et al. (2013) 'THE CONSTRUCTION OF WORLD INPUTOUTPUT TABLES IN THE WIOD PROJECT', Economic Systems Research, 25(1), pp. 71-98. doi: 10.1080/09535314.2012.761180.

E3MLab (2014) PRIMES model. Detailed model description. Athens, Greece. https://ec.europa.eu/clima/sites/clima/files/strategies/analysis/models/docs/primes_mod el_2013-2014_en.pdf. Available at: https://ec.europa.eu/clima/sites/clima/files/strategies/analysis/models/docs/primes_mod el_2013-2014_en.pdf.

E3MLab and IIASA (2016) Technical report on Member State results of the EUCO policy scenarios. Available at: https://ec.europa.eu/energy/sites/ener/files/documents/20170125__technical_report_on_euco_scenarios_primes_corrected.pdf.

European Commission (2011) A Roadmap for Moving to a Competitive Low Carbon Economy in 2050. Brussels: European Comission.

European Commission (2016a) Commission staff working document impact assessment Accompanying the document Proposal for a Directive of the European Parliament and of the Council amending Directive 2012/27/EU on Energy Efficiency. Brussels, Belgium. https://eur-lex.europa.eu/legal- 
content/EN/TXT/PDF/?uri=CELEX:52016SC0405\&from=EN. Available at: https://eurlex.europa.eu/legal-content/EN/TXT/PDF/?uri=CELEX:52016SC0405\&from=EN.

European Commission (2016b) EU reference scenario 2016: energy, transport and $G H G$ emissions: trends to 2050. Luxembourg. https://trid.trb.org/view.aspx?id=1423568. Available at: https://trid.trb.org/view.aspx?id=1423568 (Accessed: 28 November 2018).

Farley, J. and Daly, H. E. (2003) Ecological Economics: Principles and Applications. 1 edition. Washington: Island Press.

Fischer-Kowalski, M. (2011) 'Analyzing sustainability transitions as a shift between socio-methabolic regimes', Environmental Innovation and Societal Transitions., 1, pp. $152-159$.

Genty, A. (2012) 'Final database of environmental satellite accounts: technical report on their compilation'. WIOD Deliverable 4.6, Documentation. Available at: http://www.wiod.org/publications/source_docs/Environmental_Sources.pdf.

Groscurth, H.-M., Kümmel, R. and Van Gool, W. (1989) 'Thermodynamic limits to energy optimization', Energy. Pergamon, 14(5), pp. 241-258. doi: 10.1016/03605442(89)90097-2.

Hardt, L. and O’Neill, D. W. (2017) 'Ecological Macroeconomic Models: Assessing Current Developments', Ecological Economics, 134, pp. 198-211. doi: 10.1016/j.ecolecon.2016.12.027.

Hawksworth, J. (2017) The Long View: How will the global economic order change by2050? Available at: https://www.pwc.com/gx/en/world-2050/assets/pwc-theworld-in-2050-full-report-feb-2017.pdf.

Hicks, J. R. (1968) The Theory of Wages. Macmillan.

Institute for Prospective Technological Studies (2013) GEM-E3 model documentation. Available at: https://publications.europa.eu/en/publication-detail//publication/1d556dc6-d103-4b1a-8787-37ea26f2b33f/language-en (Accessed: 11 
March 2019).

IPCC (2018) 'Summary for Policymakers. In: Global Warming of $1.5^{\circ} \mathrm{C}$. An IPCC Special Report on the impacts of global warming of $1.5^{\circ} \mathrm{C}$ above pre-industrial levels and related global greenhouse gas emission pathways, in the context of strengthening the global response to', in. In Press. Available at: https://www.ipcc.ch/site/assets/uploads/sites/2/2019/05/SR15_SPM_version_report_LR .pdf.

Jackson, T. (2019) 'The Post-growth Challenge: Secular Stagnation, Inequality and the Limits to Growth', Ecological Economics, 156, pp. 236-246. doi: 10.1016/j.ecolecon.2018.10.010.

Jackson, T. and Victor, P. (2011) 'Productivity and work in the "green economy": Some theoretical reflections and empirical tests', Environmental Innovation and Societal Transitions, 1(1), pp. 101-108. doi: 10.1016/j.eist.2011.04.005.

Jackson, T. and Victor, P. A. (2019) 'Unraveling the claims for (and against) green growth', Science, 366(6468).

Kaldor, N. (1957) 'A Model of Economic Growth.', The Economic Journal, 67(268), pp. 591-624.

Kalecki, M. (1971) Selected Essays on the Dynamics of the Capitalist Economy 1933-1970. Cambridge: Cambridge University Press.

Kander, A. and Stern, D. I. (2014) 'Economic growth and the transition from traditional to modern energy in Sweden', Energy Economics, 46, pp. 56-65. doi: 10.1016/j.eneco.2014.08.025.

Krausmann, F. et al. (2008) 'The Global Sociometabolic Transition. Past and Present Metabolic Profiles and Their Future Trajectories.', Journal of Industrial Ecology, 12, pp. 637-656.

Lavoie, M. (2012) The Stock-Flow Consistent Approach. Palgrave Macmillan. Available at: https://www.palgrave.com/br/book/9780230293113 (Accessed: 11 
February 2019).

Lavoie, M. (2015) Postkeynesian Economics: New Foundations. Chentelham: Edward Elgar.

Lavoie, M. and Stockhammer, E. (2013) "“Wage-led growth: concepts, theories and policies" , Basingstoke Lavoie, M. and E. Stockhammer (2013a), , in M. Lavoie and E. Stockhammer, : Palgrave Macmillan, pp. 13-39.', in Wage-led Growth: An Equitable Strategy for Economic Recovery. Basingstoke: Palgrave Macmillan, pp. 13-39.

Lehr, U., Lutz, C. and Edler, D. (2012) 'Green jobs? Economic impacts of renewable energy in Germany', Energy Policy, 47, pp. 358-364. doi: 10.1016/j.enpol.2012.04.076.

Leimbach, M. et al. (2017) 'Future growth patterns of world regions - A GDP scenario approach', Global Environmental Change, 42, pp. 215-225. doi: https://doi.org/10.1016/j.gloenvcha.2015.02.005.

Lenton, T. M. et al. (2008) 'Tipping elements in the Earth's climate system', Proc. Natl. Acad. Sci. U.S.A., 105(6), pp. 1786-1793. doi: 10.1073/pnas.0705414105.

Leontief, W. (1970) 'Environmental Repercussions and the Economic Structure: An Input-Output Approach', The Review of Economics and Statistics, 52(3), pp. 262271. doi: $10.2307 / 1926294$.

Miller, R. E. and Blair, P. D. (2009) Input-Output Analysis. Foundations and extensions. Cambridge, UK: Cambridge University Press.

Mohr, S. H. et al. (2015) 'Projection of world fossil fuels by country', Fuel, 141, pp. 120-135. doi: 10.1016/j.fuel.2014.10.030.

Nell, E. J. (2005) The General Theory of Transformational Growth: Keynes After Sraffa. Cambridge University Press.

Nieto, J. et al. (2019) 'Macroeconomic modelling under energy constraints: Global low carbon transition scenarios', Energy Policy. Elsevier, p. 111090. doi: 10.1016/J.ENPOL.2019.111090. 
O’Neill, B. C. et al. (2017) 'The roads ahead: Narratives for shared socioeconomic pathways describing world futures in the 21st century', Global Environmental Change, 42, pp. 169-180. doi: 10.1016/j.gloenvcha.2015.01.004.

O’Neill, D. W. et al. (2018) 'A good life for all within planetary boundaries', Nature Sustainability. Nature Publishing Group, 1(2), pp. 88-95. doi: 10.1038/s41893018-0021-4.

Peng, S., Zhang, W. and Sun, C. (2016) “"Environmental load displacement” from the North to the South: A consumption-based perspective with a focus on China', Ecological Economics, 128, pp. 147-158. doi: 10.1016/j.ecolecon.2016.04.020.

Polimeni, J. M. et al. (2015) The Jevons' paradox and the myth of resource efficiency improvements.

Pollitt, H. et al. (2010) A scoping study on the macroeconomic view of sustainability - Final report for the European Commission. Cambridge, UK.

Pollitt, H. (2016) Summary of E3ME Modelling. Cambridge. Available at: https://ec.europa.eu/energy/sites/ener/files/documents/20161219__technical_report_on_macroeconomic_results_e3me.pdf.

Radzicki, M. J. and Tauheed, L. (2009) 'In Defense of System Dynamics: A Response to Professor Hayden', Journal of Economic Issues, 43(4), pp. 1043-1061. doi: 10.2753/JEI0021-3624430411.

Rezai, A., Taylor, L. and Mechler, R. (2013) 'Ecological macroeconomics: An application to climate change', Ecological Economics. (New Climate Economics), 85, pp. 69-76. doi: 10.1016/j.ecolecon.2012.10.008.

Riahi, K. et al. (2017) 'The Shared Socioeconomic Pathways and their energy, land use, and greenhouse gas emissions implications: An overview', Global Environmental Change. Pergamon, 42, pp. 153-168. doi: 10.1016/J.GLOENVCHA.2016.05.009.

Rodríguez-Huerta, E., Rosas-Casals, M. and Sorman, A. H. (2017) 'A societal 
metabolism approach to job creation and renewable energy transitions in Catalonia', Energy Policy, 108, pp. 551-564. doi: 10.1016/j.enpol.2017.06.024.

Scrieciu, S., Rezai, A. and Mechler, R. (2013) 'On the economic foundations of green growth discourses: the case of climate change mitigation and macroeconomic dynamics in economic modeling', WENE, 2(3), pp. 251-268. doi: 10.1002/wene.57.

Spash, C. L. (2016) 'The political economy of Paris Agreement on human induced climathe change: a brief guide.', Real-World Economics Review, 75, pp. 67-75. Available at: http://www.paecon.net/PAEReview/issue75/Spash75.pdf.

Steffen, W. et al. (2015) 'Planetary boundaries: Guiding human development on a changing planet', Science. American Association for the Advancement of Science, 347(6223), pp. 1259855-1259855. doi: 10.1126/science.1259855.

Tainter, J. (1988) The Collapse of Complex Societies. Cambridge: Cambridge University Press.

Tainter, J. (2011) 'Energy, complexity, and sustainability: A historical perspective', Environmental Innovation and Societal Transitions(, 1, pp. 89-95.

Taylor, L., Rezai, A. and Foley, D. K. (2016) 'An integrated approach to climate change, income distribution, employment, and economic growth', Ecological Economics, 121, pp. 196-205. doi: 10.1016/j.ecolecon.2015.05.015.

Timmer, M. et al. (2015) 'An Illustrated User Guide to the World Input-Output Database: the Case of Global Automotive Production', Review of International Economics, 23(3), pp. 575-605. Available at: http://econpapers.repec.org/article/blareviec/v_3a23_3ay_3a2015_3ai_3a3_3ap_3a575605.htm (Accessed: 29 June 2017).

Uehara, T., Nagase, Y. and Wakeland, W. (2013) 'Integrating Economics and System Dynamics Approaches for Modeling an Ecological-Economic System', Systems Science Faculty Publications and Presentations. Available at: http://pdxscholar.library.pdx.edu/sysc_fac/63. 
Victor, P. A. (2008) Managing Without Growth: Slower by Design, Not Disaster. Cheltenham, UK ; Northampton, MA: Edward Elgar Publishing.

Wu, Y., Zhu, Q. and Zhu, B. (2018) 'Comparisons of decoupling trends of global economic growth and energy consumption between developed and developing countries', Energy Policy, 116, pp. 30-38. doi: 10.1016/j.enpol.2018.01.047. 